(C) The Authors 2016

\title{
Reversibility of endothelial dysfunction in diabetes: role of polyphenols
}

\author{
N. Suganya ${ }^{1}$, E. Bhakkiyalakshmi ${ }^{1}$, D. V. L. Sarada ${ }^{1}$ and K. M. Ramkumar ${ }^{2 *}$ \\ ${ }^{1}$ Department of Biotechnology, School of Bioengineering, SRM University, Kattankulathur 603 203, Tamil Nadu, India \\ ${ }^{2}$ SRM Research Institute, SRM University, Kattankulathur 603 203, Tamil Nadu, India \\ (Submitted 11 November 2015 - Final revision received 5 April 2016 - Accepted 6 April 2016)
}

\begin{abstract}
The endothelium, a thin single sheet of endothelial cells, is a metabolically active layer that coats the inner surface of blood vessels and acts as an interface between the circulating blood and the vessel wall. The endothelium through the secretion of vasodilators and vasoconstrictors serves as a critical mediator of vascular homeostasis. During the development of the vascular system, it regulates cellular adhesion and vessel wall inflammation in addition to maintaining vasculogenesis and angiogenesis. A shift in the functions of the endothelium towards vasoconstriction, proinflammatory and prothrombic states characterise improper functioning of these cells, leading to endothelial dysfunction (ED), implicated in the pathogenesis of many diseases including diabetes. Major mechanisms of ED include the down-regulation of endothelial nitric oxide synthase levels, differential expression of vascular endothelial growth factor, endoplasmic reticulum stress, inflammatory pathways and oxidative stress. ED tends to be the initial event in macrovascular complications such as coronary artery disease, peripheral arterial disease, stroke and microvascular complications such as nephropathy, neuropathy and retinopathy. Numerous strategies have been developed to protect endothelial cells against various stimuli, of which the role of polyphenolic compounds in modulating the differentially regulated pathways and thus maintaining vascular homeostasis has been proven to be beneficial. This review addresses the factors stimulating ED in diabetes and the molecular mechanisms of natural polyphenol antioxidants in maintaining vascular homeostasis.
\end{abstract}

\section{Key words: Polyphenols: Endothelial dysfunction: Diabetes: Cell signalling}

\section{Endothelial cells and their vascular functions}

Endothelial cells lining the lumen of the vascular bed serve as a metabolic interface between blood and tissues, which is indispensable for the maintenance of vascular homeostasis ${ }^{(1)}$. These cells are the predominant players in regulating a variety of blood vessel functions including blood fluidity and passage of nutrients, hormones and macromolecules to the surrounding tissues $^{(2)}$. The major functions of endothelial cells including maintenance of vascular tone, cell adhesiveness, platelet aggregation, leucocyte trafficking, coagulation cascade, inflammation, permeability, regulation of thrombosis and fibrinolysis $^{(1,3)}$ will be discussed in the following section (Fig. 1).

\section{Vascular tone}

The degree of constriction experienced by a blood vessel relative to its maximally dilated state is referred to as the vascular tone, which is modulated by the release of endothelium-derived relaxing and constricting factors ${ }^{(4)}$.
The vasoprotective effects of a healthy endothelium are vasodilation, suppression of smooth muscle cell growth and inhibition of inflammatory responses, in which the vasodilators act against the effects of endothelium-derived vasoconstrictors. Vascular tone is maintained by homeostasis between the vasodilators such as nitric oxide (NO*), prostacyclin (PGI2) and endothelium-derived hyperpolarising factor and vasoconstrictors, including endothelin-1 (ET-1), angiotensin II (Ang II), thromboxane A2 (TXA2) and platelet-activating factor released by the endothelial cells ${ }^{(5)}$. Damage to the endothelium creates an imbalance between vasodilation and vasoconstriction, resulting in the initiation of a cascade of events such as increased endothelial permeability, platelet aggregation, leucocyte adhesion and generation of cytokines ${ }^{(6)}$.

\section{Coagulation and fibrinolysis}

Endothelial cells have major roles in regulating haemostatic balance, preventing the activation of thrombin and inhibiting platelet adhesion, thereby mediating anticoagulant $\operatorname{activity}^{(7)}$.

\footnotetext{
Abbreviations: ADMA, asymmetric dimethylarginine; AGE, advanced glycation end products; AMPK, AMP-activated protein kinase; $\mathrm{BH}_{4}$, (6R)-5,6,7,8tetrahydro-L-biopterin; cGMP, cyclic GMP; EGCG, epigallocatechin gallate; eNOS, endothelial nitric oxide synthase; ER, endoplasmic reticulum; ET-1, endothelin-1; GLP-1, glucagon-like peptide-1; ICAM, intracellular adhesion molecule; IRE1, inositol-requiring enzyme 1; IRS-1, insulin receptor substrate 1; Nrf2, nuclear factor-E2-related factor 2; MCP-1, monocyte chemoattractant protein-1; NO*, nitric oxide; NOX, NADPH oxidase; PKC, protein kinase C; ROS, reactive oxygen species; SGLT2, sodium-glucose co-transporter 2; STZ, streptozotocin; T1D, type 1 diabetes; T2D, type 2 diabetes; UPR, unfolded protein responses; VCAM, vascular cell adhesion molecule; VEGF, vascular endothelial growth factor; XO, xanthine oxidase.
} 
(a)
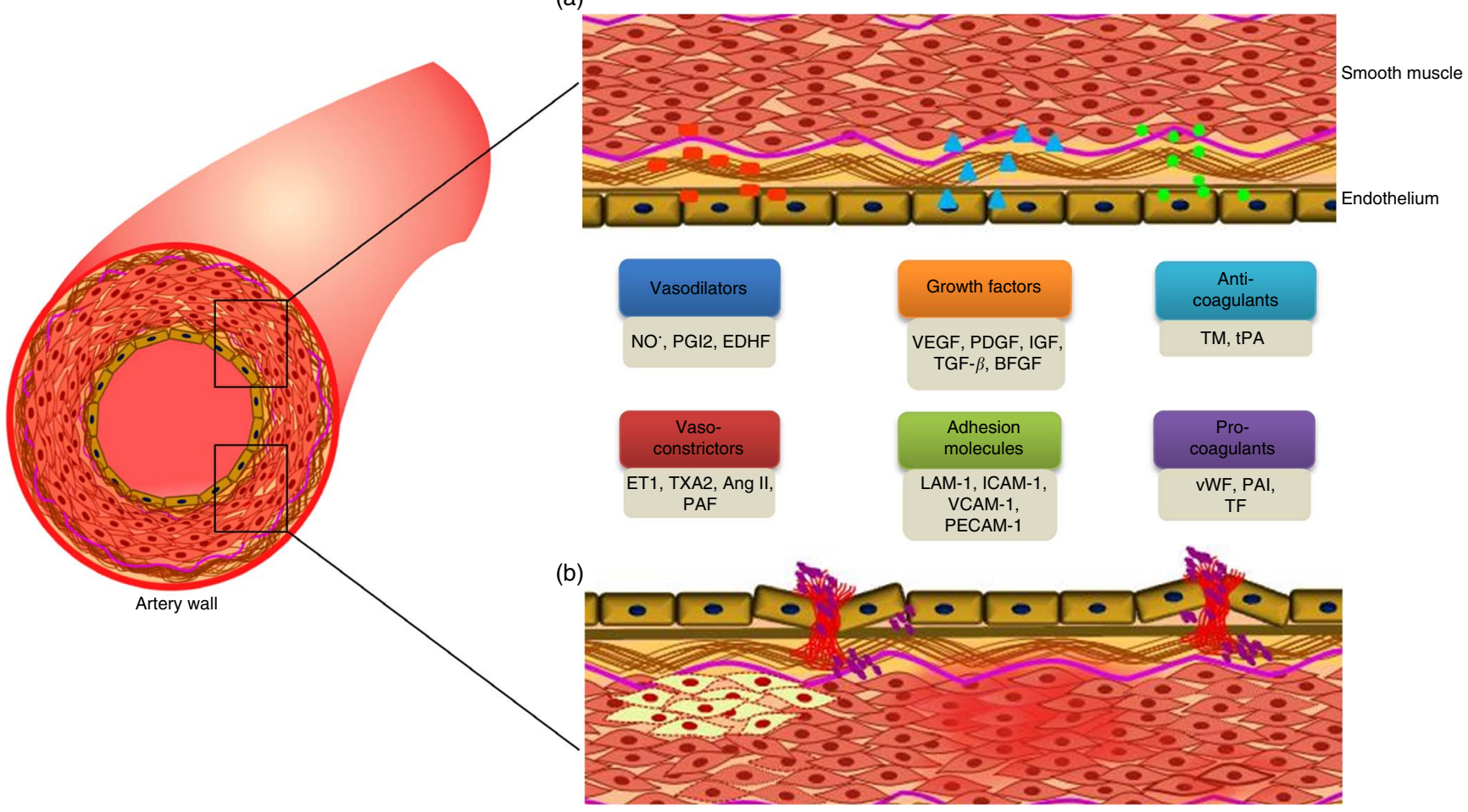

Fig. 1. Factors secreted by endothelium, and its functions. (a). A healthy endothelium mediates endothelium-dependent vasodilation and suppresses thrombosis and inflammation. It displays the vasodilatory function with high levels of vasodilators such as nitric oxide (NO), prostacyclin (PGI2) and endothelium-derived hyperpolarising factors (EDHF). It plays a vital role in cell proliferation and differentiation function with the secretion of growth factors such as vascular endothelial growth factor (VEGF), platelet-derived growth factor (PDGF), insulin-like growth factor (IGF), transforming growth factor- $\beta$ (TGF- $\beta$ ), and basic fibroblast growth factor (bFGF). It also has an anticoagulative phenotype with the release of thrombomodulin (TM) and tissue plasminogen activator (tPA). (b). A dysfunctional endothelium mediates vasoconstriction with the secretion of endothelin-1 (ET1), thromboxane A2 (TXA2), angiotensin II (Ang II) and platelet-activating factor (PAF). Endothelial cell inflammation has been associated with the expression of cell adhesion molecules such as leucocyte adhesion molecule-1 (LAM-1), intercellular adhesion molecule 1 (ICAM-1), vascular cell adhesion molecule 1 (VCAM-1) and platelet cell adhesion molecule-1 (PECAM-1). In addition, it secretes pro-coagulants such as von Willebrand factor (VWF), plasminogen activator inhibitor type-1 (PAI-1) and tissue factor (TF). A colour figure is available in the online version of the paper.

These cells secrete an integral membrane protein, thrombomodulin, which causes a reduction in blood coagulation along with the assistance of platelet tissue factor, plasminogen activator inhibitor-1 (PAI-1) and urokinase-type plasminogen activator $^{(8)}$. The release of endothelial products by thrombin has a critical role in coagulation, inflammation and vascular homeostasis, which is largely arbitrated by the thrombin receptor, also known as protease-activated receptor-1 (PAR-1). The activation of PAR-1 mediates intracellular signalling pathways by (a) enhancement in the production of $\mathrm{NO}^{-}$and PGI2, which induce vasodilation and regulation of platelet activation; (b) stimulating tissue plasminogen activator (tPA), which binds to fibrin and mediates effective fibrinolysis; and (c) activation of Weibel-Palade bodies that release von Willebrand factor (vWF), angiopoietin-2 and P-selectin, which are involved in the modulation of inflammatory response ${ }^{(9)}$.

\section{Cell growth and differentiation}

The synchronised regulation of vasculogenesis or de novo differentiation of bone marrow-derived endothelial progenitor cells (EPC), that is, angioblasts into endothelial cells followed by angiogenesis, is essential for the development of the vascular system. Angiogenesis is the major mechanism of vascularisation involving endothelial cell sprouting, vessel branching and intussusceptions of the vasculature from the pre-existing blood vessels $^{(10)}$. Vascular endothelial growth factor (VEGF) secreted by the endothelial cells is known to be the main growth factor specific for the vascular endothelium, and hence expression of VEGF receptors has been considered a critical regulator of endothelial cell development ${ }^{(11)}$. Expression of growth factors such as fibroblast growth factor, heparin-binding epidermal growth factor, platelet-derived growth factor (PDGF) and transforming growth factor $\beta$ in addition to tyrosine kinase receptors tie-2 (tek) and angiopoietins (Ang-1 and Ang-2) assists in the vascular development and promotes angiogenesis, a major event in embryonic development, regeneration and wound healing ${ }^{(12)}$.

\section{Adhesion and permeability}

Endothelial cells produce specific adhesion molecules, namely E-selectin, intracellular adhesion molecule (ICAM) and vascular cell adhesion molecule (VCAM), for the regulation of cell adhesion and permeability ${ }^{(13)}$. The intact endothelium expresses low levels of these adhesion molecules, and upon activation, over-expression of these molecules has been reported, which play a role in maintaining endothelial barrier integrity 
and also mediate paracellular and transcellular migration ${ }^{(14)}$. In addition, leucocyte passage from blood to underlying tissues involves the interaction between leucocyte carbohydrate ligand and endothelial E- and P-selectins. Further, firm adhesion mediated by the interactions between leucocyte integrins and endothelial adhesion molecules and their up-regulation increases endothelial permeability ${ }^{(15)}$. Moreover, binding and accumulation of circulating cells such as platelets, leucocytes and erythrocytes to the endothelial cells restricts blood flow ${ }^{(16)}$.

\section{Endothelial dysfunction}

The inability of the endothelium to maintain vascular homeostasis is referred to as endothelial dysfunction, a systemic pathological state that alters endothelial cell phenotype, characterised by a shift in the normal functions of the endothelium towards reduced vasodilation, proinflammatory and prothrombic state. Endothelial dysfunction is triggered by a number of factors including turbulent blood flow, shear stress, hypoxia, ageing, hyperglycaemia, hypercholesterolaemia and hypertension ${ }^{(17,18)}$. The pathophysiology of endothelial dysfunction in diabetes, an initial event in the development of microvascular and macrovascular complications, is emphasised. The microvascular complications in diabetes encompass long-term complications affecting small blood vessels including diabetic retinopathy, nephropathy and neuropathy. The macrovascular complications include the diseases of large blood vessels throughout the body including coronary and peripheral arteries leading to cardiovascular and cerebrovascular diseases and stroke.

\section{Factors promoting endothelial dysfunction in diabetes}

Vascular homeostasis regulates glucose metabolism in the endothelial cells by balancing insulin levels and stimulating glucose transport ${ }^{(19)}$. High glucose disrupts the vascular homeostasis and promotes both microvasculature and macrovasculature modifications by induction of phenotypic switch and altering intracellular signalling pathways. In the recent years, significant achievements have been made in understanding the mechanism of endothelial cell dysfunction triggered under diabetic conditions and the differences in etiopathogenesis between type 1 diabetes (T1D) and type 2 diabetes (T2D). In T1D, uncontrolled hyperglycaemia with low levels of endogenous insulin mediates endothelial dysfunction $^{(20)}$, whereas the pathogenesis of endothelial dysfunction in T2D involves effects of fatty acids and insulin resistance $^{(21)}$. The metabolic milieu in diabetes, i.e. hyperglycaemia, insulin resistance, hyperinsulinemia and obesity, induces a wide range of events. The major causal factors for endothelial dysfunction including oxidative stress, endoplasmic reticulum (ER) stress and inflammation ${ }^{(22,23)}$ are over-viewed below (Fig. 2).

\section{Hyperglycaemia}

Increased blood glucose level, the hallmark of diabetes, is a major risk factor for endothelial dysfunction-mediated vascular complications. In hyperglycaemia, endothelial dysfunction is triggered by the inhibition of the glycolytic enzyme, D-glyceraldehyde 3-phosphate dehydrogenase. This causes accumulation of glycolytic intermediates leading to the activation of major metabolic pathways such as the protein kinase C (PKC) pathway, the hexosamine pathway and the sorbitol pathway ${ }^{(24)}$, in addition to the generation of methylglyoxal and advanced glycation end products (AGE).

Accumulated evidence shows altered phenotype of endothelial cell including apoptosis ${ }^{(25)}$ through the activation of

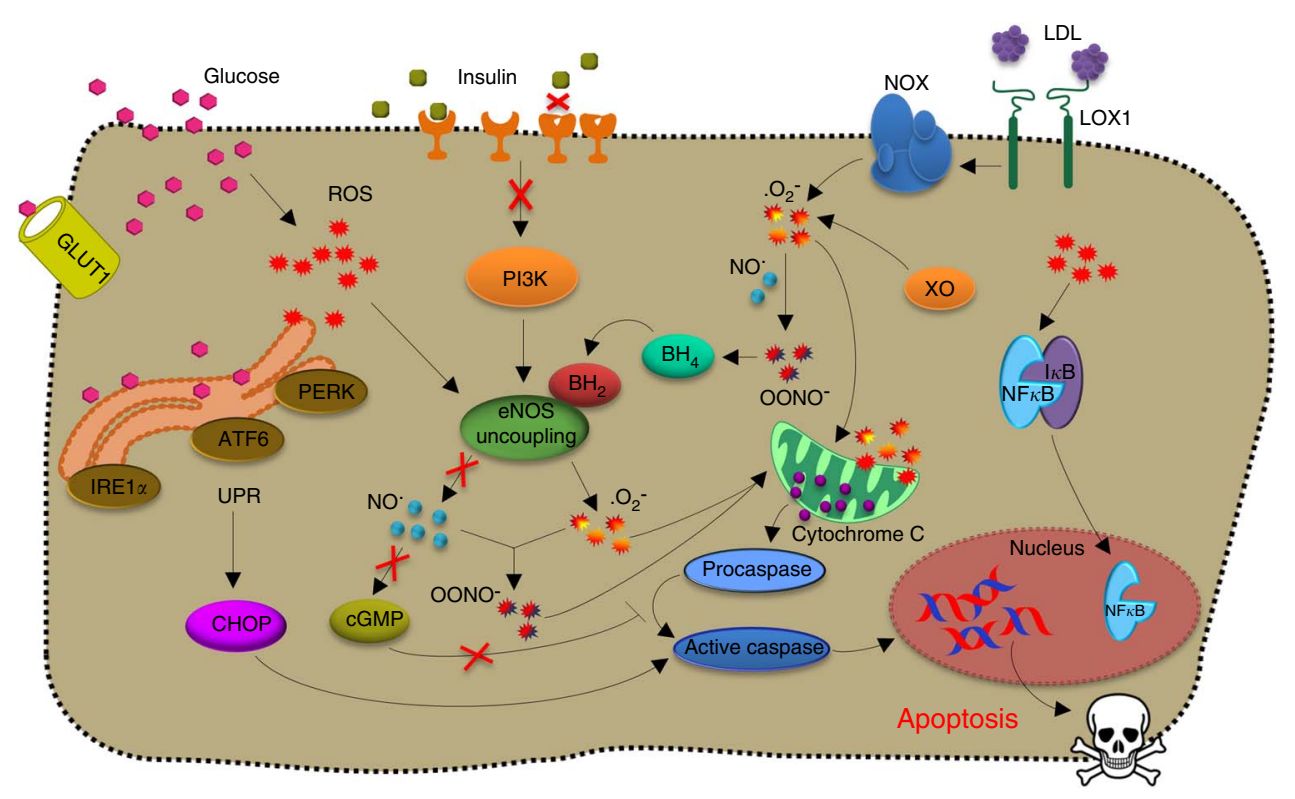

Fig. 2. Fate of endothelial cells in diabetes. Hyperglycaemia, insulin resistance and obesity interrupt normal endothelial cell functions and promote the generation of reactive oxygen species (ROS). Induction of oxidative and endoplasmic reticulum (ER) stresses up-regulate inflammatory and apoptotic pathways leading to apoptosis. IER1a, inositol-requiring enzyme 1a; ATF6, activating transcription factor 6; PERK, protein kinase RNA-like endoplasmic reticulum kinase; UPR, unfolded protein responses; CHOP, C/ERB homologous protein; cGMP, cyclic GMP; eNOS, endothelial nitric oxide synthase; XO, xanthine oxidase; NOX, NADPH oxidase; LOX1, LDL receptor $1 ; \mathrm{BH}_{4},(6 \mathrm{R})-5,6,7,8$-tetrahydro-L-biopterin; $\mathrm{NO}^{-}$, nitric oxide;. $\mathrm{O}_{2}^{-}$, superoxide; $\mathrm{ONOO}^{-}$, peroxynitrite. A colour figure is available in the online version of the paper. 
caspases, increased reactive oxygen species (ROS) and inflammatory markers ${ }^{(26)}$ because of increased glucose concentration in the blood, altered metabolic activity with increased levels of lipid peroxidation products ${ }^{(27)}$ and enhanced intracellular calcium levels ${ }^{(28)}$. In addition, high glucose also triggers the production of vasoconstrictors such as prostanoids and thromboxanes, resulting in vascular contractility. Further alteration in insulin signalling mediates an increase in the levels of vasoactive peptides such as Ang II and ET-1, contributing to endothelial dysfunction ${ }^{(29)}$.

\section{Insulin resistance}

Under physiological conditions, insulin delivery is the rate-limiting step in insulin-stimulated glucose uptake in the skeletal muscle. This is mediated by the involvement of endothelial cells, which regulate the capillary recruitment and glucose uptake $^{(30)}$. Insulin resistance is associated with the impairment of GLUT-4 translocation in fat tissues and muscles with reduced $\mathrm{NO}^{\bullet}$ production, this weakens the insulin signalling and glucose uptake, mediating vasodilation ${ }^{(31)}$. Attenuation of Akt phosphorylation in response to insulin ${ }^{(32)}$ has been reported in the microvascular endothelial cells in T2D models resulting from impairment of the phosphoinositide 3-kinase-protein kinase $\mathrm{B}$ (PI3K-Akt) pathway.

\section{Hyperinsulinemia}

Metabolic insulin resistance is usually accompanied by increased levels of circulating insulin or hyperinsulinemia which impairs endothelial function ${ }^{(33)}$. Imbalance in $\mathrm{PI} 3 \mathrm{~K}-$ and mitogenactivated protein kinase (MAPK)-dependent functions of insulin and down-regulation of endothelial nitric oxide synthase (eNOS) has been evidenced in hyperinsulinemia ${ }^{(34)}$. Elevated insulin levels stimulate VCAM-1 and E-selectin through the MAPKdependent pathway and ET-1 secretion, causing pronounced abnormal vascular function ${ }^{(35)}$. ET-1 induces NAD(P)H oxidase (NOX) expression with increased generation of superoxide anion $\left(. \mathrm{O}_{2}^{-}\right)$, as reported in rat aortic endothelium ${ }^{(36)}$. Hyperinsulinemia also contributes to cellular hypertrophy with increased synthesis and accumulation of elements of the extracellular matrix, thereby altering the structure of the vessel wall ${ }^{(37)}$.

\section{Obesity and dyslipidaemia}

Metabolic disorders including obesity, hypertension and lipid abnormalities linking atherosclerosis cluster with insulin resistance. Dyslipidaemia and obesity are the major risk factors for cardiovascular events in diabetes ${ }^{(38)}$. It has been demonstrated that obesity induces endothelial dysfunction before the development of insulin resistance ${ }^{(39)}$. In T2D, the reduced endothelium-dependent vasodilation is mediated by the attenuation of $\mathrm{NO}^{\circ}$ production, decreased sensitivity to $\mathrm{NO}^{\bullet}$ decreased Akt phosphorylation and enhanced vasoconstrictor tone ${ }^{(40-42)}$. The abnormal lipids affect endothelial cells directly, by the activation of lectin-like oxidised LDL receptor, stimulation of NOX-dependent. $\mathrm{O}_{2}^{-}$formation and release of cytokines, culminating in apoptosis ${ }^{(43)}$.

\section{Oxidative stress}

Increased oxidative stress has been reported to be a common feature of endothelial dysfunction often associated with NOX, xanthine oxidase (XO), aldehyde oxidase and glucose oxidase, the enzymes involved in the generation of ROS.

\section{Mitochondrial reactive oxygen species production.} Mitochondria are known to be one of the major intracellular sources of ROS production, formed as a by-product of oxidative phosphorylation along the respiratory chain ${ }^{(44)}$. Increasing evidence suggests that morphological and functional changes in mitochondria of diabetic subjects are linked to vascular complications ${ }^{(45)}$. Davidson et al. reported hyperglycaemia to be associated with impaired mitochondrial activity in vascular tissues leading to ROS-mediated endothelial dysfunction ${ }^{(46)}$. Excess ROS lead to mitochondrial fragmentation in coronary endothelial cells of T1D mice ${ }^{(47)}$. In addition, increased ROS alters mitochondrial calcium homeostasis and hence mediates various vascular complications ${ }^{(48,49)}$. Hence, ROS generation and calcium overload exacerbate mitochondrial metabolism that represents a principal step in the development of endothelial dysfunction.

NADPH oxidase. NOX, is a transmembrane enzyme and a major source of. $\mathrm{O}_{2}^{-}$and hydrogen peroxide $\left(\mathrm{H}_{2} \mathrm{O}_{2}\right)$ in the vascular cells ${ }^{(50)}$. Physiologically, NOX-derived ROS has been implicated in the regulation of vascular tone either directly by modulating vasodilation or indirectly by quenching. $\mathrm{O}_{2}^{-}$to form peroxynitrite $\left(\mathrm{ONOO}^{-}\right)^{(51)}$, thus decreasing $\mathrm{NO}^{\bullet}$ bioavailability. It also exhibits a pathophysiological role in provoking endothelial dysfunction, inflammation, hypertrophy, apoptosis, migration, fibrosis, angiogenesis and important processes underlying cardiovascular and renal remodelling in hypertension and diabetes. Hyperglycaemia has also been reported to increase lung vascular permeability with increased generation of vascular. $\mathrm{O}_{2}^{-}$through $\mathrm{NOX}^{(52)}$.

Xanthine oxidase. XO uses molecular $\mathrm{O}_{2}$ as an electron acceptor producing. $\mathrm{O}_{2}^{-}$and $\mathrm{H}_{2} \mathrm{O}_{2}$. It acts as an important biological source of ROS, and its involvement in various pathological processes, including diabetes, has been well documented ${ }^{(50,53)}$. The circulating and tissue XO levels contribute to increased . $\mathrm{O}_{2}^{-}$production and have been reported in both diabetic animals as well as diabetic patients ${ }^{(54,55)}$. Increased expression of XO results in ATP:ADP ratio imbalance and elevated levels of ROS in streptozotocin (STZ)-induced diabetic mice, demonstrating the role of the enzyme in the pathogenesis of endothelial dysfunction $^{(53)}$. It has also been observed that treatment of diabetic animals with allopurinol, a potent inhibitor of $\mathrm{XO}$, improved endothelium-dependent vasodilation and reduced diabetic complications ${ }^{(55)}$.

It is clear that the increase in NOX and XO contributes to ROS production in mitochondria, which in turn mediates eNOS uncoupling thereby triggering endothelial dysfunction. Inhibition of NOX and $\mathrm{XO}$ abolishes the increase in mitochondrial ROS, thus preventing eNOS uncoupling. 
Endothelial nitric oxide synthase uncoupling. $\mathrm{NO}^{\bullet}$ is a potent endogenous vasodilator produced by the enzyme nitric oxide synthase (NOS). eNOS produces $\mathrm{NO}^{-}$which is involved in various physiological events and is a critical regulator of endothelial cell migration, survival and angiogenesis ${ }^{(56)}$. Studies relate reduced $\mathrm{NO}^{\circ}$ production in diabetes to the pathogenesis of diabetic endothelial dysfunction ${ }^{(57,58)}$. Functional eNOS oxidises its substrate L-arginine to $\mathrm{L}^{-c i t r u l l i n e}$ and $\mathrm{NO}^{\bullet}$ by dimerisation of the enzyme with the presence of an essential cofactor, (6R)-5,6,7,8-tetrahydro-L-biopterin $\left(\mathrm{BH}_{4}\right)$, which is one of the potent naturally occurring reducing agents ${ }^{(59,60)}$. $\mathrm{NO}^{\bullet}$ then activates the enzyme guanylate cyclase, resulting in the formation of cyclic GMP (cGMP), a critical second messenger responsible for initiation and maintenance of vasorelaxation ${ }^{(61)}$. Diminished levels of $\mathrm{BH}_{4}$ due to its oxidation into $\mathrm{BH}_{2}$ promotes. $\mathrm{O}_{2}^{-}$production by eNOS, referred to as 'eNOS uncoupling ${ }^{, 56)}$. Inactivation of $\mathrm{NO}^{\bullet}$ by. $\mathrm{O}_{2}^{-}$and other ROS tends to be the major mechanism in impaired vasoregulation ${ }^{(62)}$. eNOS uncoupling-mediated endothelial dysfunction has been documented in diabetes ${ }^{(63)}$. Meanwhile, few reports evidenced that eNOS uncoupling linked to reduced $\mathrm{BH}_{4}$ availability resulted in the production of. $\mathrm{O}_{2}^{-}$radicals rather than $\mathrm{NO}^{\bullet}(64,65)$. Further, the prevention of PKC-mediated activation of NOX caused a reduction in eNOS uncoupling and. $\mathrm{O}_{2}^{-}$production via the inhibition of vascular $\mathrm{ONOO}^{-}$formation and decreased oxidation of $\mathrm{BH}_{4}$, in STZ-induced diabetic rats ${ }^{(66)}$. The supplementation of $\mathrm{BH}_{4}$ has been reported to improve endotheliumdependent vasodilation by increasing $\mathrm{NO}^{\bullet}$ activity in $\mathrm{T} 2 \mathrm{D}$ patients ${ }^{(59,60)}$.

Excess. $\mathrm{O}_{2}^{-}$inhibits the enzyme dimethylarginine dimethylaminohydrolase (DDAH), which mediates the accumulation of asymmetric dimethylarginine (ADMA), an endogenously produced inhibitor of $\mathrm{NOS}^{(67)}$. This elevated ADMA inhibits $\mathrm{NO}^{\circ}$ synthesis by eNOS or uncouples the enzyme, which in turn enhances oxidative stress ${ }^{(56,68)}$. Reports highlight elevated plasma ADMA levels to be the risk factors for cardiovascular events and kidney disease in both T1D and T2D patients ${ }^{(69,70)}$. Increased oxidative stress in the vasculature is not restricted to the endothelium but also affects the smooth muscle cell layer. Increased. $\mathrm{O}_{2}^{-}$production by the endothelial cells has important consequences in eNOS uncoupling and its downstream signalling, resulting in decreased expression of soluble guanylyl cyclase and the cGMP-dependent protein kinase I, which controls vessel tone and smooth muscle cell proliferation ${ }^{(68,71)}$.

\section{Endoplasmic reticulum stress}

ER stress known as unfolded protein responses (UPR) has a crucial role in the pathogenesis of diabetes, contributing to pancreatic $\beta$-cell loss and insulin resistance. Vascular endothelial cells of hyperglycaemic subjects are characterised by altered rough endoplasmic reticulum (rER) and protein folding, which leads to ER stress ${ }^{(38,72)}$. As reported by Sheikh-Ali et $a l^{(72)}$, hyperglycaemia-induced ER stress in endothelial cells may be initiated through different stress signalling molecules of the glucose metabolism such as pyruvate, glycerol and dihydroxyacetone. The accumulation of unfolded or misfolded proteins in the ER initially restores the normal function of ER by halting translation, degrading misfolded proteins and activating signalling pathways to increase molecular chaperones involved in protein folding. Sustained UPR has been implicated in the initiation of several cell death pathways mediated by the activation of caspase-12 ${ }^{(73)}$, apoptosis signal-regulating kinase 1 , the c-Jun N-terminal kinase (JNK) pathway ${ }^{(74)}$, the protein kinase RNA-like-like endoplasmic reticulum kinase (PERK) pathway and $\mathrm{C} / \mathrm{ERB}$ homologous protein $(\mathrm{CHOP})$ pathway ${ }^{(75)}$. Provoked ER stress increases the activity of JNK and catalytic $\mathrm{I} \kappa \mathrm{B}$ kinase subunits and induces inflammation associated with impairment of insulin receptor substrate 1 (IRS-1) signalling, thus linking diabetes and vascular endothelial dysfunction ${ }^{(12,76)}$.

\section{Effect of hyperglycaemia on the blood vessels}

Hyperglycaemia activates the hexosamine pathway leading to the formation of $\mathrm{O}$-linked $\mathrm{N}$-acetylglucosamine ( $\mathrm{O}$-GlcNAc) in the blood vessels. In the vasculature, it competes with NOS phosphorylation and impairs $\mathrm{NO}^{\circ}$-mediated arteriolar dilations. The more $\mathrm{O}$-GlcNAc, the less $\mathrm{NO}^{\bullet}$ produced in the vasculature leading to vasoconstriction, thus increasing the risk of high blood pressure in diabetic subjects ${ }^{(77)}$. In addition, an elevated level of $O$-GlcNAc impairs angiogenesis in endothelial cells, by inhibiting Akt signalling, cell migration and capillary-like structure formation ${ }^{(78)}$. In T2D subjects, the lymphatic barrier dysfunction reduces lymph flow, thereby trapping lipids and cholesterol in the tissue, inhibiting lymphatic transport of cholesterol bound to HDL from the tissues to the liver, aggravating atherosclerosis and dyslipidaemia ${ }^{(79)}$.

Insulin is a known vasodilator that increases blood flow mainly by stimulating $\mathrm{NO}^{\bullet}$ synthesis ${ }^{(80)}$. Baron et al. ${ }^{(81)}$ demonstrated that insulin controls its own access and that of other substrates such as glucose, lipids and several signalling molecules to peripheral tissues, by increasing blood flow, but this effect is compromised in states of insulin resistance. It has been shown that insulin infusion increases myocardial blood flow in both T1D and $\mathrm{T} 2 \mathrm{D}^{(82,83)}$

The role of insulin in regulating glucose availability is well established in peripheral tissues, such as skeletal muscle and adipose tissues. Insulin normally stimulates capillary recruitment of skeletal muscle and subcutaneous adipose tissue, thus increasing blood flow mainly after a meal or physical exercise. This function is impaired in insulin resistance and T2D, reflecting early onset of vascular dysfunction. Failure of insulin to increase muscular and adipose tissue blood flow consequently decreases glucose disposal. Numerous studies have shown that in states of decreased insulin sensitivity the postprandial blood flow in adipose tissue is reduced ${ }^{(84)}$. Reports highlight insulin enhancement of NOS-dependent vascular actions, increased total muscular blood flow and recruitment of muscle capillaries ${ }^{(85)}$.

\section{Diabetes-mediated structural alterations in endothelial cells}

Under normal physiological conditions, endothelial cells show stable interaction with smooth muscle surface and scanty organelles with flat nucleus, separated from the underlying connective tissues by a thin, extracellular matrix of tissues 
named as 'basal lamina', which functions in heterotypic tissue interactions. In addition, normal endothelial cells are actively engaged in transcytosis, a process by which the transcellular transfer of molecules across the endothelium takes place ${ }^{(86)}$.

The ultrastructure of the endothelial cell and the extracellular matrix tends to be altered under hyperglycaemia. A significant enrichment of biosynthetic organelles such as golgi complex in the aortic and capillary endothelial cells, abundance of rER in aortic arch of retinal venules and femoral artery have been reported $^{(87)}$. Further predominant thickening of endothelial cell basal lamina accounting to impairment in the circulation of metabolic products between tissues ${ }^{(88)}$ has been reported (Fig. 3). Hyperglycaemia also mediates endothelial dysfunction by causing endothelial barrier injury leading to hyperpermeability and plasma leakage ${ }^{(89)}$.

\section{Antidiabetic drugs improving endothelial function}

Currently available conventional therapies for diabetes are supported by clinical and preclinical evidences that are aimed at improving endothelial function. Some of the antidiabetic agents such as metformin, glucagon-like peptide-1 (GLP-1) receptor agonists, inhibitors of phosphodiesterase-5 (PDE5), dipeptidyl peptidase-4 (DPP4) and sodium-glucose co-transporter 2 (SGLT2) act in different modes to preclude diabetic complications especially by preventing endothelial dysfunction, which is a key event in the pathogenesis.

\section{Metformin}

Metformin, an antidiabetic drug, significantly improved endothelium-dependent vasodilator response. Reduction in the levels of endothelial markers such as vWF, VCAM-1, tPA, PAI-1 and ICAM- ${ }^{(90)}$ have been reported to be the mechanism underlying the protective effects of metformin. In addition, long-term treatment with metformin improved endothelial function and decreased inflammatory response ${ }^{(91)}$.

\section{Glucagon-like peptide-1 receptor agonists}

GLP-1 receptor agonists mimic GLP-1 and increase incretin effect in patients with T2D. They stimulate the release of insulin and improve the endothelial function through direct vascular action $^{(92)}$. Recent report showed that exenatide, a GLP-1 receptor agonist, reverted glucose- and lipid-induced endothelial dysfunction. Exenatide activated eNOS and $\mathrm{NO}^{\bullet}$ production in endothelial cells, in addition to induced vasorelaxation and reduced endothelial dysfunction in arterioles ${ }^{(93)}$. In obesity and pre-diabetic patients, exenatide treatment showed a significant change in inflammation and oxidative stress status. Effects of exenatide have also improved postprandial vascular endothelial dysfunction in T2D patients ${ }^{(94)}$.

\section{Phosphodiesterase-5 inhibitors}

PDE5 is a cytosolic enzyme that primarily functions to degrade cGMP and induce vasoconstriction. PDE5 inhibitors up-regulate eNOS transcription and increase $\mathrm{NO}^{\bullet}$ release, causing long-term vasodilator effects. They are also reported for improving endothelium-dependent vasorelaxation in diabetic rats and for their potential to reduce glomerular hypertension in diabetic nephropathy ${ }^{(95)}$. Sildenafil, a PDE5 inhibitor, attenuates diabetic nephropathy in Otsuka Long-Evans Tokushima Fatty rats ${ }^{(96)}$

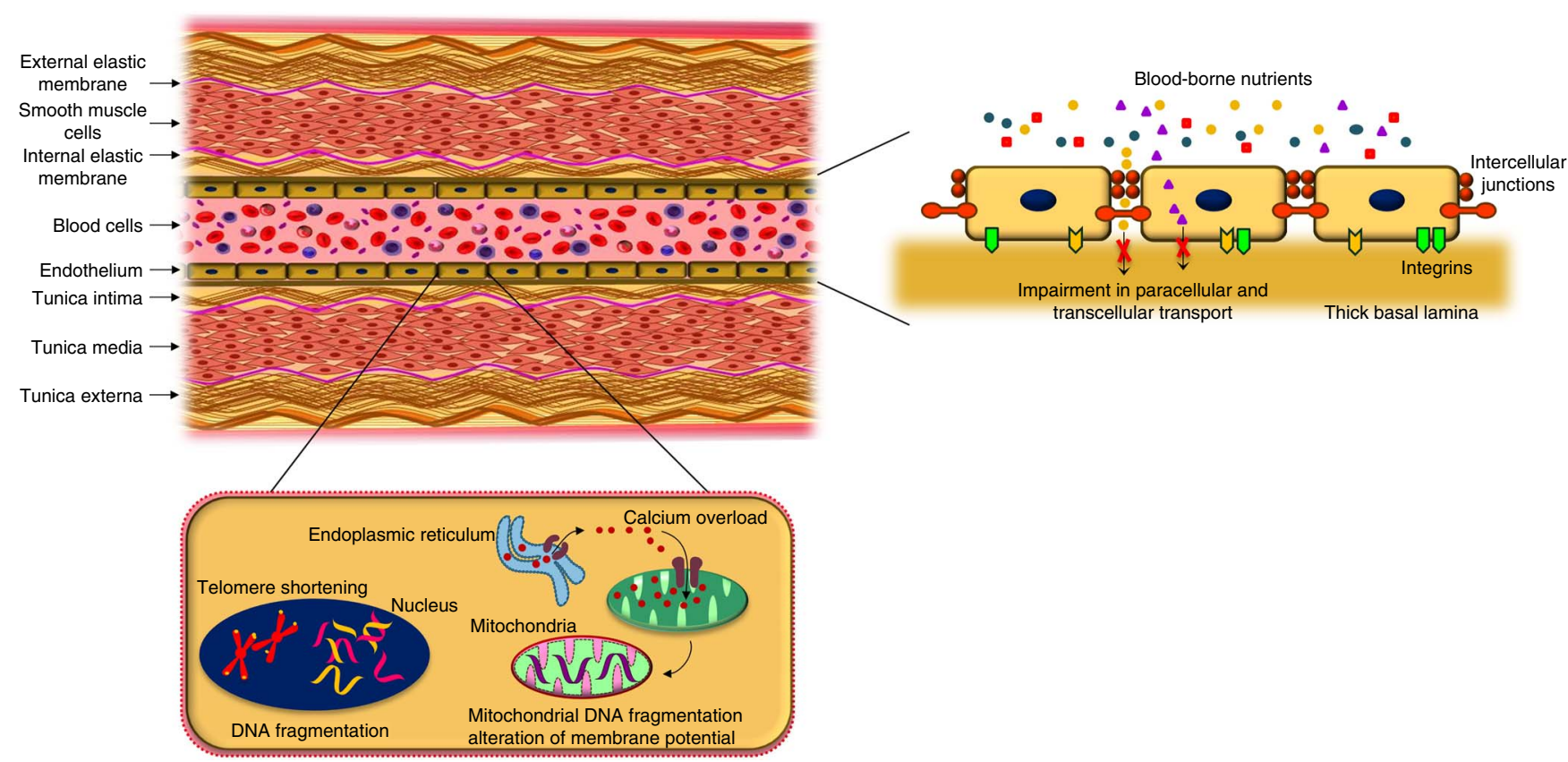

Fig. 3. Structural modifications in endothelial cells under hyperglycaemia. Hyperglycaemia induced thickening of endothelial basal lamina impairs the transport of metabolic products and nutrients between blood and tissues. Further, hyperglycaemia induces telomere shortening, DNA fragmentation, intracellular calcium enhancement leading to mitochondrial calcium overload causing mitochondrial DNA fragmentation and alteration in membrane potential. A colour figure is available in the online version of the paper. 


\section{Dipeptidyl peptidase-4 inhibitor}

Endothelial cells are the main endogenous sources of DPP4, an enzyme involved in inactivating active GLP-1 (7-36) to GLP-1 (9-36). The inhibitors of DPP-4 have been used in the treatment of $\mathrm{T} 2 \mathrm{D}^{(92)}$. DPP 4 interacts with pro-inflammatory pathways and impairs endothelial function through incretin-dependent and incretin-independent mechanisms. It has been reported that the DPP-4 inhibitor des-fluoro-sitagliptin enhanced acetylcholine-induced endothelium-dependent vasodilatation in mouse aortic rings ${ }^{(97)}$. Vildagliptin, another DPP-4 inhibitor, improved endothelial function, as indicated by measurement of forearm blood flow during acetylcholine infusion in T2D patients $^{(98)}$

\section{Sodium-glucose co-transporter inhibitors}

A newly developed therapeutic strategy for the treatment of diabetes is the use of the SGLT2 inhibitors, which offer a novel insulin-independent approach for the control of hyperglycaemia and are currently in phase 2 and 3 clinical trials. These inhibitors target the SGLT2, the main GLUT in the kidney that is also responsible for the reabsorption of $>90 \%$ of the glucose in the kidney ${ }^{(99)}$. SGLT2 inhibition reduces the reabsorption of glucose and therefore enhances urinary glucose excretion preventing glucotoxicity and consequently decreasing both fasting and postprandial hyperglycaemia. SGLT2 inhibitor therapy has been reported to reverse glucose-induced vascular dysfunction by reducing glucotoxicity, oxidative stress, inflammation and restoring insulin signalling, thereby reversing endothelial dysfunction ${ }^{(100)}$. Empagliflozin has been reported to cause reduction in cellular glucotoxicity, prevention of oxidative stress, AGE signalling and inflammation via NOX inhibition, decreased AGE precursor and methylglyoxal thereby maintaining the normal endothelial function in STZ-animal T1D model ${ }^{(100)}$. In addition, SGLT-2 inhibitors improved the vascular architecture in connective tissue participating in arterial stiffening and regulated $\mathrm{NO}^{\circ}$-dependent relaxation in mouse pulmonary arteries ${ }^{(101)}$.

\section{Alternative treatment strategies}

Adverse side effects of currently available therapies for diabetes and their associated complications added to the insufficiency in meeting the increasing therapeutic demand warrants the development of alternative approaches for the treatment and prevention of fatal vascular complications. A promising strategy encompasses the use of antioxidants, such as vitamins, that reduce oxidative stress. In addition, exercise training, organic nitrate and nitrite, tetrahydrobiopterin, L-arginine, taurine and magnesium supplementation are the other therapeutic possibilities for endothelial dysfunction in diabetes.

\section{Exogenous nitrate treatment}

Administration of exogenous $\mathrm{NO}^{\bullet}$ in the form of organic nitrates rather than improving vascular function leads to an increased formation of $\mathrm{ONOO}^{-}$mediating adverse effects. In particular, nitroglycerin induces clinical tolerance, oxidative stress and endothelial dysfunction similar to other nitrates such as isosorbide-5-mononitrate (ISMN) and isosorbide dinitrate. These are more likely to induce endothelial dysfunction and increase oxidative stress via activation of the vascular NOX. In contrast, pentaerythritol tetranitrate (PETN) reduces oxidative stress in vascular tissue through its interaction with the powerful antioxidant enzyme heme oxygenase-1 (HO-1). Regulation of cardiac oxidative stress and lipid peroxidation in STZ-induced diabetic rats treated with PETN treatment proved a clear correlation between NOX activity, endothelial dysfunction and nitrate resistance ${ }^{(102)}$. In STZ-induced rats, PTEN treatment prevented the activation of NOX, inhibited XO-mediated. $\mathrm{O}_{2}^{-}$ production, eNOS uncoupling and thereby reduced oxidative stress, which was not the case with ISMN. In addition, PETN modified the metabolism of glucose in diabetic rats via the AMP-activated protein kinase (AMPK) pathway ${ }^{(103)}$.

\section{Exercise}

Moderate exercise tends to be the stimulator of $\mathrm{NO}^{\circ}$ release, and it influences endothelial function, which in turn reduces the cardiovascular profile in diabetic patients ${ }^{(104)}$. It has been reported that exercise training improved the vascular endothelial function in patients with long-term $\mathrm{T}_{10}^{(105)}$. Currently, the beneficial effects of exercise training in T2D patients have been well established. Participation in regular physical activity maintained glucose metabolism, improved energy metabolism and insulin sensitivity and delayed T2D by attenuating the lipid profile, blood pressure and cardiovascular events $^{(106,107)}$. Lee et $a l^{(108)}$ demonstrated that exercise recovered eNOS phosphorylation, increased antioxidant enzymes such as superoxide dismutase (SOD)-1 and SOD-2, increased $\mathrm{NO}^{\bullet}$ bioavailability and also decreased pro-inflammatory cytokines such as TNF- $\alpha$ and IL- 6 , in the T2D mouse model.

\section{Antioxidant therapy}

Antioxidants have been accounted to improve endothelial dysfunction in diabetes by re-coupling eNOS and mitochondrial function, by increasing the activity of. $\mathrm{O}_{2}^{-}$scavenging enzymes or by decreasing vascular NOX activity.

Vitamin C. In endothelial cells, L-ascorbic acid blocks the oxidative stress-induced increase in endothelial permeability by maintaining $\mathrm{NO}^{\bullet}$ levels $^{(109)}$. In adults with T1D, the combination of euglycaemia and ascorbic acid therapy has been observed to normalise endothelial function ${ }^{(110)}$ in addition to the reduction in acute hyperglycaemia-induced impairment of endothelial function ${ }^{(111)}$. L-Ascorbic acid reversed the endothelial dysfunction in patients with coronary artery disease. The study of Heitzer et al. highlighted the mechanism of oxidative stress-driven progression of atherosclerotic disease and the beneficial effect of vitamin $\mathrm{C}$ in scavenging the increased. $\mathrm{O}_{2}^{-}$-derived free radicals. The positive response to vitamin $\mathrm{C}$ has been documented against the higher risk of 
cardiovascular events where oxidative stress has a major role ${ }^{(59)}$. Vitamin $\mathrm{C}$ has been also reported to improve the endothelium-dependent, $\mathrm{NO}^{\circ}$-mediated vasodilation in diabetic patients, in relation to an imbalance between increased oxidative stress and depleted antioxidant defence. Further, endothelium-dependent vasodilation has been improved by a supraphysiological concentration of vitamin $\mathrm{C}^{(59)}$. A recent study showed that ascorbic acid supplementation ameliorated skeletal muscle oxidative stress during hyperinsulinemia and improved insulin-mediated glucose disposal in $\mathrm{T} 2 \mathrm{D}^{(112)}$.

Folic acid. Folic acid, a tetrahydrofolic acid precursor, has been shown to improve endothelial dysfunction in patients with $\mathrm{T}_{1} \mathrm{D}^{(113)}$ and $\mathrm{T} 2 \mathrm{D}^{(114)}$ by potentially reversing the uncoupling of eNOS. The reduced folate levels have been associated with reduced flow-mediated vasodilation in T1D patients, which demonstrates the direct effect of folic acid on endothelial function $^{(115)}$. On the contrary, latter studies demonstrated that folic acid fails to improve endothelial dysfunction in diabetic nephropathy patients ${ }^{(116)}$. Furthermore, increased cancer incidence and mortality with folate and vitamin $\mathrm{B}_{12}$ supplementation have limited their use ${ }^{(117)}$.

Vitamin D. Low vitamin D levels have been associated with an increased risk of cardiovascular disease and endothelial dysfunction in adults with diabetes ${ }^{(118)}$. Evidence demonstrates that a single large dose of vitamin D markedly improved flowmediated vasodilation in adult $\mathrm{T} 2 \mathrm{D}^{(119)}$. Vitamin $\mathrm{D}$ is a natural ER stress reliever, and the absence of vitamin $\mathrm{D}$ receptor in macrophages triggers ER stress in T2D patients ${ }^{(120)}$.

Vitamin E. Vitamin $\mathrm{E}$ has a potential to prevent hyperglycaemia-induced endothelial dysfunction, as demonstrated in in vivo models. Deficiency of vitamin E is deleterious for endothelial function in diabetes. Hyperglycaemia-induced reduction in basal $\mathrm{NO}^{\bullet}$ production has been significantly prevented by vitamin E supplementation ${ }^{(121)}$. A study with T1D patients showed that vitamin $\mathrm{E}$ improved the endothelial vasodilator function $^{(122)}$ as well as enhanced vascular reactivity of micro- and macrocirculation ${ }^{(123)}$.

\section{Polyphenols in the amelioration of endothelial dysfunction}

Numerous therapeutic strategies have been developed for restoring endothelial dysfunction under diabetic conditions. In addition to antioxidant therapy, many studies also confirmed the protective effects of polyphenol antioxidants against diabetic vascular complications ${ }^{(124,125)}$. Many clinical trials have revealed the beneficial activity of these polyphenol antioxidants against endothelial dysfunction; for example, the effects of green tea and cocoa polyphenols against endothelial dysfunction in patients with diabetes, red-wine polyphenols against microvascular dysfunction and citrus fruit consumption on vascular protection ${ }^{(126,127)}$. The major drawbacks in the effects of polyphenol antioxidants are (i) their presence in large amounts in natural food, (ii) differences in their bioavailability $^{(128)}$ and (iii) the chemical nature of the active component, which might not be polyphenol but its derivative ${ }^{(129)}$.

Other limitations of the currently available interventional trials are the relatively short duration of the therapy, inadequacy of the doses of antioxidants used and the timing of the initiation of antioxidant therapy ${ }^{(130)}$. However, a detailed scientific investigation of polyphenol antioxidants confirmed that this tends to be the safe and effective approach for diabetes and its vascular complications. In addition, results from several experimental studies suggested that polyphenol antioxidants improved endothelial function by multiple mechanisms. Extensive literature demonstrates the beneficial effect of polyphenol antioxidants on endothelial dysfunction and revealed $\mathrm{NO}^{\bullet}$ signalling pathway as a major target in diabetes management.

The molecular mechanisms underlying the antioxidant properties of polyphenols and some of the important signalling pathways mediating vascular endothelial cell protection under hyperglycaemia including (i) NO` signalling pathway, (ii) VEGFmediated angiogenic pathway, (iii) ER stress pathway, (iv) inflammatory and (v) nuclear factor-E2-related factor 2 (Nrf2)mediated antioxidant pathway (Fig. 4) are discussed.

\section{Nitric oxide signalling}

$\mathrm{NO}^{\bullet}$ production in endothelial cells is mainly regulated by the constitutive expression of eNOS in the presence of its substrate L-arginine and cofactors such as NADPH, FAD, FMN and $\mathrm{BH}_{4}^{(131)}$. eNOS is regulated at multiple sites by phosphorylation of serine (Ser), threonine (Thr) and tyrosine (Tyr) residues by Akt kinase, cyclic AMP (cAMP)-dependent PKA and AMPK in endothelial cells ${ }^{(132,133)}$. Further, the activation of IRS-1 by insulin subsequently phosphorylates eNOS through PI3K/Akt signalling pathways ${ }^{(134)}$. eNOS is activated in response to fluid shear stress and numerous agonists via cellular events such as increased intracellular calcium, interaction with substrate and cofactors, protein phosphorylation and cellular factors such as VEGF, IGF and so on. Dysregulation of these processes attenuates eNOS expression and reduces $\mathrm{NO}^{\bullet}$ levels, a characteristic of numerous pathophysiological disorders, including diabetes. Under conditions of insulin resistance, IRS-1 mutation reduces the insulin-stimulated eNOS phosphorylation in endothelial cells ${ }^{(135)}$ and impairs $\mathrm{NO}^{\circ}$ bioavailability ${ }^{(136)}$ through PI3k/Akt signalling. In addition, NOX localised in the endothelium serves as a major source of. $\mathrm{O}_{2}^{-}$, and its interaction with eNOS leads to uncoupling, which is implicated in diabetic complications ${ }^{(137)}$. OONO $^{-}$formed by the reaction of $\mathrm{NO}^{\bullet}$ with $\mathrm{O}_{2}^{-}$reduces the availability of $\mathrm{NO}^{*}$, causing induction of VCAM-1, ICAM-1 and E-selectin in endothelial cells ${ }^{(138)}$. The activated endothelium expresses chemotactic factors such as monocyte chemoattractant protein-1 (MCP-1) and other proinflammatory cytokines such as macrophage colony-stimulating factor and TNF- $\beta$. Expression of these factors contributes to the development of inflammation within the arterial wall and promotes atherogenesis.

Modulation of $\mathrm{NO}^{\bullet}$ and the role of antioxidants in restoring endothelial dysfunction is gaining momentum. Polyphenol antioxidants are being investigated for enhancement of the 


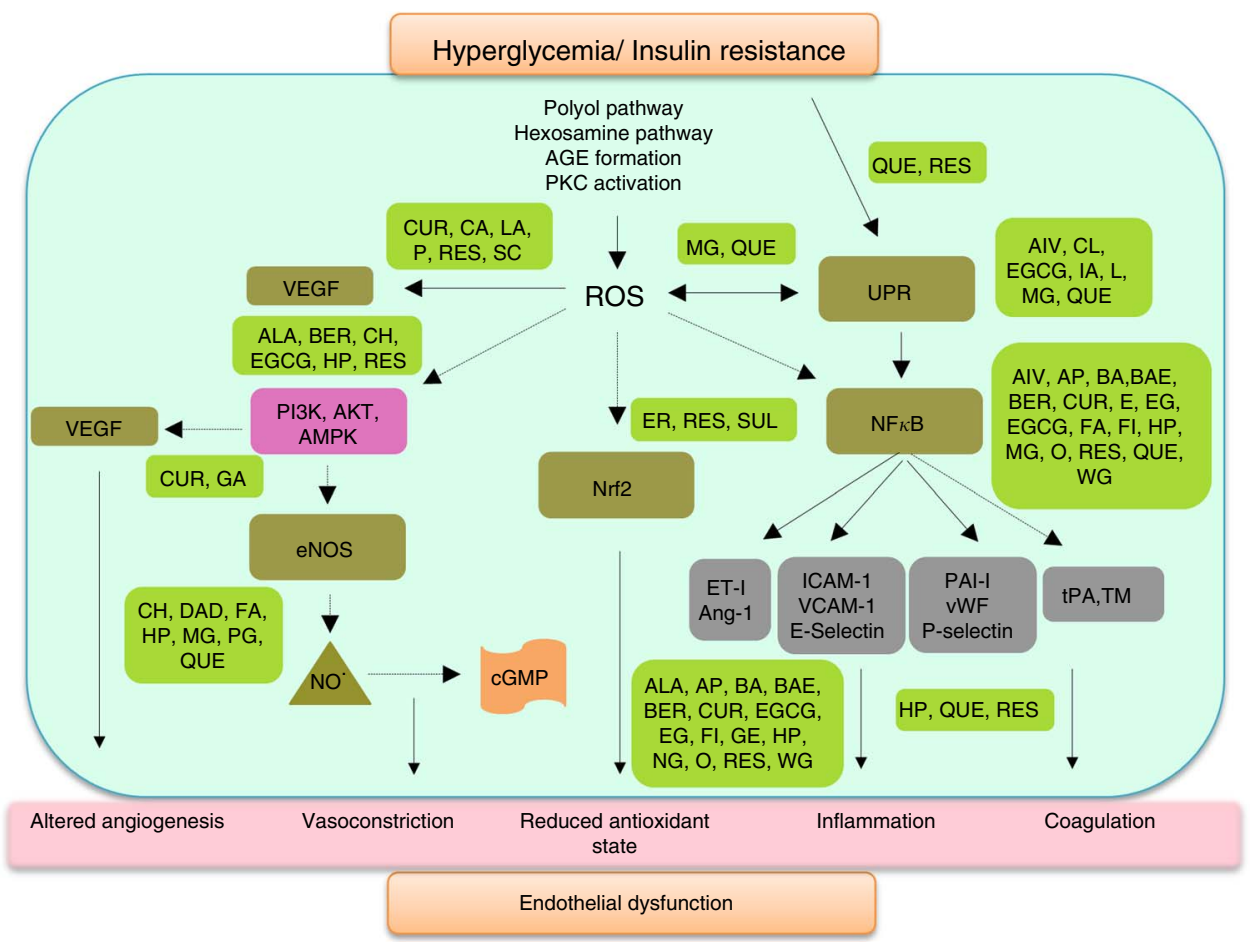

Fig. 4. Various signalling targets of polyphenol antioxidants in endothelial cell protection. AIV, astragoloside; ALA, a linolenic acid; AP, apigenin, BA, baicalin; BAE, baicalein; BER, berberine; CA, chlorogenic acid; $\mathrm{CH}$, catechin hydrate; CL, cycloastragenol; CUR, curcumin; DAD, daidzein; EG, emodin-6-O- $\beta$-D-glucoside; E, emodin; EGCG, epigallocatechin gallate; ER, eriodictyol; FA, ferulic acid; FI, fisetin; GA, gallic acid; GE, genistein; HP, hesperetin; IA, ilexgenin A; L, luteolin; LA, a-lipoic acid; MG, mangiferin; NG, naringin; O, orientin; P, paeonol; PG, propyl gallate; QUE, quercetin; RES, resveratrol; SC, scutellarein; SUL, sulforaphane; WG, wogonin; AMPK, AMP-activated protein kinase; eNOS, endothelial nitric oxide synthase; NO, nitric oxide; cGMP, cyclic GMP; Nrf2, nuclear factor-E2-related factor 2; UPR, unfolded protein responses; ET-1, endothelin-1; Ang-1, angiopoietin 1; ICAM-1, intracellular adhesion molecule 1; VCAM-1, vascular cell adhesion molecule 1; PAI-1, plasminogen activator inhibitor-1; vWF, von Willebrand factor; tPA, tissue plasminogen activator; TM, thrombomodulin. A colour figure is available in the online version of the paper.

release of $\mathrm{NO}^{\bullet}$ from the endothelium to assess the possibility of reversing endothelial dysfunction caused by decreased production of $\mathrm{NO}^{\bullet}$ in diabetes. Polyphenols are considered to be the most effective antioxidants. One of the most studied polyphenols, resveratrol, is present in red grapes and other fruits. It has been reported to restore the IRS-1/Akt/eNOS signalling pathway in endothelial cells under palmitate-induced insulin resistance ${ }^{(139)}$. Further, resveratrol is effective in restoring the vascular functions mediated through eNOS in diabetic rats ${ }^{(140)}$.

Machha et al. ${ }^{(141)}$ reported modulation of endothelium-derived $\mathrm{NO}^{\bullet}$ bioavailability in aortic tissues of diabetic rats by quercetin, a flavonol. Recently, the effect of quercetin against highglucose-induced toxicity mediated by sirtuin 1-dependent eNOS and intracellular cGMP expression in bone marrow-derived $\mathrm{EPC}^{(142)}$ has been reported. The vasoprotective role of quercetin has also been evidenced by phosphorylating eNOS at Ser1179 through cAMP/PKA signalling and enhancing the production of $\mathrm{NO}^{\bullet(143)}$.

Gallic acid, a trihydroxy benzoic acid, restored eNOS activity in glomerular endothelial cells of diabetic rats through oxidative stress reduction in diabetic nephropathy ${ }^{(144,145)}$. Daidzein, a phyto-oestrogen, reversed changes in vascular reactivity through NO ${ }^{\bullet}$ and PG-related pathways, and attenuated oxidative stress in aortic tissue of diabetic rats ${ }^{(146)}$. Other polyphenolic compounds such as epigallocatechin gallate (EGCG), hesperetin, $\alpha$-linolenic acid, ferulic acid and catechin hydrate have also been reported to reverse endothelial dysfunction through the activation of the PI3K/ Akt/eNOS pathway, as demonstrated in both in vitro and in vivo diabetic models ${ }^{(147-151)}$.

ADMA, the endogenous NOS inhibitor, is disposed to be one of the causative factors in endothelial dysfunction. Tang et $a{ }^{(152)}$ demonstrated that EGCG, a polyphenolic catechin, attenuated endothelial dysfunction in diabetic models by decreasing ADMA level via increasing DDAH activity. In addition, silibinin, a flavonolignan, markedly improved endothelial function in T2D mice by reducing circulating and vascular ADMA levels ${ }^{(153)}$.

The protective role of berberine, an alkaloid, has been reported to increase the expression of AMPK and eNOS, whereas it down-regulates NOX, thereby ameliorating endothelial dysfunction in palmitate-exposed endothelial cells ${ }^{(154)}$. Wang et $a l .^{(155)}$ showed that berberine attenuated high-glucose-induced endothelial dysfunction through the activation of AMPK/eNOS signalling, mediating NO ${ }^{\bullet}$ and cGMP production, and endothelium-dependent vasodilatation.

\section{Vascular endothelial growth factor-mediated angiogenesis}

VEGF, a potent pro-angiogenic growth factor, and its receptors in endothelial cells promote angiogenesis and cell proliferation ${ }^{(156)}$. Under diabetic conditions, elevated VEGF level acts as a 
pathological angiogenic stimulus leading to ocular neovascularisation (retinopathy) and nephropathy, whereas low levels of VEGF activity lead to cardiomyopathy and peripheral neuropathy because of insufficient angiogenesis ${ }^{(157)}$. The relationship between VEGF and vascular complications is an intricate process, particularly in patients with diabetes. This situation provides an insight into the complicated interplay between VEGF, VEGF receptors and the resulting systemic effects on microvascular and macrovascular diseases ${ }^{(157)}$.

In diabetic retinopathy, VEGF receptors are up-regulated in retinal endothelial cells. Increased VEGF favours the proteolysis of endothelial basement membrane, which is the limiting step in angiogenesis, leading to retinopathy. In addition, a direct correlation between VCAM-1 and VEGF in the vitreous fluid of retinopathy patients has been reported ${ }^{(158)}$. VEGF and its receptor expression levels are critical in maintaining normal glomerular podocytes and renal tubular function. VEGF expressed in glomerular podocytes activates VEGF receptor 2 on glomerular capillary endothelial cells, regulating endothelial fenestrations and permeability ${ }^{(159)}$. Hyperglycaemia together with ROS elevates VEGF level and increases glomerular permeability, hyperfiltration and hypertrophy contributing to diabetic nephropathy ${ }^{(160)}$.

Diabetic macrovascular complications such as cardiomyopathy are characterised by impaired angiogenesis. Cardiomyopathy, an inability of the heart to circulate blood throughout the body, has been reported with reduced myocardial VEGF and its receptor expressions. In addition, it results in decreased capillary density accompanied by decreased myocardial perfusion and progressive left ventricular dysfunction ${ }^{(161)}$. VEGF has an important role in nerve regeneration, and its regulation reflects the functional state of peripheral nerves. It protects the dorsal root ganglia against diabetes-induced neurotoxicity. The reduced levels of VEGF under hyperglycaemia lead to late-onset motor neuron degeneration ${ }^{(162)}$. Under hyperglycaemic conditions, impaired wound healing mediated by down-regulation of VEGF receptors results in impaired angiogenesis, which in turn is the cause for EPC dysfunction, low platelet count, reduced granulation and defective lymphatic vasculature ${ }^{(163)}$.

Reversal from endothelial dysfunction, evidenced by a few polyphenol antioxidants, is effected by down-regulation of angiogenesis mediated by VEGF. Curcumin, a well-known antioxidant, inhibits VEGF expression in STZ-induced diabetic retina and kidney, thereby mediating vascular protection ${ }^{(164-166)}$. Chlorogenic acid found abundantly in coffee significantly decreased VEGF levels and thereby reduced retinal vascular hyperpermeability and leakage in the diabetic retinopathy ${ }^{(167)}$ rat model.

VEGF mediates the activation of $\mathrm{PKC}$, and its translocation to endothelial cell membranes triggers the angiogenesis process $^{(168)}$. The antiangiogenic activity of curcumin was demonstrated in human retinal endothelial cells reported to be caused by a reduction in glucose-induced mRNA levels of VEGF expression, and it also inhibits PKC $\beta$ II translocation induced by $\mathrm{VEGF}^{(169)}$. The protective role of paeonol has been studied against high-glucose-induced vascular endothelial cell injury in a co-culture model system with vascular smooth muscle cells. Restored vascular homeostasis was evidenced by downregulation of VEGF and PDGF-B, rat sarcoma (Ras), phosphorylated rapidly accelerated fibrosarcoma (p-Raf) and phosphorylated extracellular signal-regulated kinases (p-ERK) protein expressions in the vascular smooth muscle cells ${ }^{(170)}$. Scutellarein, a flavone found in Scutellaria lateriflora, suppresses VEGF and cell proliferation ${ }^{(171)}$ in high-glucose-treated human retinal endothelial cells. Resveratrol down-regulated VEGF/ fetal liver kinase-1 (Flk-1) (VEGF receptor-2) expression and thereby modulated hyperpermeability and junction disruption in glomerular endothelial cells. It also ameliorates high-glucoseinduced hyperpermeability mediated by overexpressed caveolin1 in aortic endothelial cells ${ }^{(172)}$.

$\mathrm{R}-(+)-\alpha$-lipoic acid inhibits VEGF-stimulated proliferation in microvascular and macrovascular endothelial cell isolated from the diabetic patients independent of their vascular origin. It reduces both apoptosis and proliferation of retinal endothelial cells through the activation of Akt and retinoblastoma protein transcription factor (E2F-1) ${ }^{(173)}$. Hyperglycaemia and increased AGE in diabetes cause inactivation of the VEGF receptors such as Flk-1 and hence altered VEGF expression, affecting endothelial growth and migration $^{(174)}$. VEGF is vital in promoting collateral vessel formation after ischaemic events and plays a key role in wound healing ${ }^{(156)}$. Defective wound healing in diabetic patients is often associated with impaired VEGF expression resulting in failure to form the vasculature ${ }^{(175)}$. VEGF also mediates the survival of immature vessels through Flk-1 via the PI3K/Akt pathway ${ }^{(176)}$. In addition to cell growth, VEGF inhibits apoptosis through the Akt pathway ${ }^{(177)}$. Nakamura et $a l .{ }^{(178)}$ demonstrated the antiapoptotic potential of VEGF in EPC isolated from cord blood through the activation of Akt signalling. The abnormal cross talk between VEGF-A and $\mathrm{NO}^{\circ}$ pathways is fuelled by the hyperglycaemiainduced oxidative stress ${ }^{(179)}$.

Yang et al. reported that the elevated glucose downregulated VEGF through attenuation of p42/44 MAPK phosphorylation with the activation of mitochondrial apoptosis pathway mediated by ROS and Ca leading to endothelial dysfunction. Restoration of VEGF explains its role in apoptosis inhibition with a decrease in the B-cell lymphoma 2-associated X protein:B-cell lymphoma 2 (Bax:Bcl-2) ratio, thereby inhibiting caspase-3 activation ${ }^{(180)}$.

With cultured human glomerular endothelial cells under high-glucose and vascular endothelial growth factor receptor 1 (VEGFR1) inhibition, induced apoptosis and oxidative stress are mediated by the suppression of PI3K-Akt phosphorylation ${ }^{(181)}$. T2D mice with VEGFR1 inhibition showed apoptosis of the glomerular cells with albuminuria, mesangial matrix expansion and inflammatory cell infiltration, with the inactivation of eNOSNOx signalling. The uncoupling of the VEGF-NO ${ }^{\bullet}$ axis in the glomeruli resulting from eNOS inactivation has been reported in glomerular endothelial dysfunction ${ }^{(182)}$. Tian et al. ${ }^{(145)}$ confirmed the improvement of glomerular pathological changes in diabetic rats through oxidative stress reduction and VEGF-NO axis recovery and prevention of glomerular endothelial dysfunction by propyl gallate.

\section{Endoplasmic reticulum stress pathway}

ER is the organelle in which proteins fold and attain their native conformation and post-translational modifications such as 
$N$-linked glycosylation, disulfide bond formation, lipidation, hydroxylation and oligomerisation ${ }^{(183)}$. Any perturbation in the protein folding machinery leads to the accumulation of unfolded/misfolded proteins and activates UPR. Elevation in levels of glucose, oxidised phospholipids and homocysteines disturbs the endothelial cells and trigger ER stress ${ }^{(184,185)}$. As a counter mechanism to maintain ER homeostasis, UPR up-regulates ER chaperons and foldases, and activates endoplasmic reticulum-associated degradation and also down-regulates the expression of secretory proteins, thereby reducing the accumulation of unfolded proteins ${ }^{(186)}$. ER stress sensors such as PERK, inositol-requiring enzyme 1 (IRE1) and activating transcription factor 6 (ATF6) play a central role in the initiation and regulation of $\mathrm{UPR}^{(187)}$. However, when the stress is beyond the holding capacity of UPR, it up-regulates IRE1, which activates JNK signalling and caspase- $12^{(188)}$; in addition to CHOP activation via phosphorylation ${ }^{(189)}$, these events culminate in the suppression of the antiapoptotic protein $\mathrm{Bcl}-2$, rendering the cells to undergo apoptosis ${ }^{(190)}$.

The ER stress responses has been implicated in the endothelial dysfunction observed in T1D, T2D and obesity ${ }^{(191,192)}$. Experimental conditions mimicking hyperglycaemia with supra-physiological dextrose concentrations and over-expression of exogenous GLUT-1 increased the ER stress in human umbilical vein endothelial cells (HUVEC) ${ }^{(72)}$. It has also been evaluated that ER stress activates IRE1 via JNK phosphorylation. It perturbs insulin signalling in endothelial cells by inhibiting IRS-1 and reducing NO production ${ }^{(38)}$. PERK mediated hyperglycaemiainduced endothelial inflammation and retinal vascular leakage in T1D mouse model ${ }^{(191)}$, and endothelial cell apoptosis under highglucose conditions have been reported ${ }^{(193)}$

Experimental evidence spotlights ER stress to be a major causative factor for neurodegenerative diseases in diabetes $^{(72,194)}$. For instance, ER stress is a potential mediator of inflammation in diabetic retinopathy ${ }^{(195)}$, which has been well documented with the experiment of Chen et al. ${ }^{(191)}$. Moreover, diabetic retinopathy-associated distorted retinal angiogenesis has been linked to ER stress ${ }^{(196,197)}$. Hence, inhibition of ER stress and its specific mediators has been acknowledged to be a potential target for vascular complications under hypeglycaemia. Antioxidants such as $\alpha$-tocopherol and ascorbic acid did not ameliorate glucose-induced ER stress condition ${ }^{(198)}$. Research studies focusing on endothelial ER stress under hyperglycaemic conditions are limited, and only few polyphenolic compounds are reported to overcome the UPR. Recent research with human endothelial cells by Song et al. indicated provoking of ER stress with increased ROS production in hyperglycaemia. Mangiferin, a polyphenolic compound, effectively inhibited ER stress-associated oxidative stress by reducing ROS production and by attenuating IRE1 phosphorylation ${ }^{(199)}$.

Inflammasome is a multiprotein intracellular complex and an innate immune system receptor that regulates the activation of caspase- 1 and induces inflammation under stress conditions $^{(200)}$. The important components of the inflammasome complex include the nucleotide-binding domain and leucinerich repeat-containing proteins (also known as NOD (nucleotide oligomerisation domain)-like receptors (NLR)) ${ }^{(201)}$. Upon sensing stress stimuli, the relevant NLR activates caspase-1, which subsequently functions to cleave the proinflammatory IL- 1 cytokines into their active forms: IL- $1 \beta$ and IL-18. It has been reported that ER-activated inflammasome formation evokes endothelial inflammation and apoptosis, playing a critical role in the onset of endothelial dysfunction $^{(202)}$. Mangiferin, a xanthonoid, has been reported to reduce the expression of thioredoxin-interacting protein (TXNIP) and its NOD-like receptor protein 3 (NLRP3) inflammasome. It also inhibited ER stress-associated IRE1 $\alpha$ phosphorylation and regulated endothelial homeostasis in an AMPK-dependent manner ${ }^{(199)}$

Polyphenolic compound combinations such as quercetin, luteolin and EGCG alleviate palmitate-induced ER stress in endothelial cells. They were found to maintain the endothelial homeostasis by inhibiting ER stress-associated TXNIP and NLRP3 inflammasome activation, and they restored mitochondrial function and protected cells against inflammation and $\operatorname{apoptosis}^{(203)}$. Few other compounds such as ilexgenin $\mathrm{A}^{(204)}$, astragaloside IV and cycloastragenol ${ }^{(205)}$ have been reported to improve endothelial function under palmitate-induced ER stress in an AMPK-dependent manner and by inhibiting TXNIP/NLRP3 inflammasome pathway.

Experimental ER stress has been induced with pharmacological agents such as thapsigargin, tunicamycin, A23187 and brefeldin $\mathrm{A}^{(206)}$. The contemplated possible involvement of ER stress in endothelial dysfunction has been studied by our group in tunicamycin-induced HUVEC. Tunicamycin blocks $\mathrm{N}$-glycosylation of proteins and causes an extensive protein misfolding, thus activating UPR in the endothelial cells ${ }^{(207)}$. The protective effect of quercetin against the activation of ER stress was attributed to the up-regulation of markers such as $78 \mathrm{kDa}$ glucose-regulated protein (GRP78), a molecular chaperone and CHOP in unresolved diabetic and experimental ER stress conditions ${ }^{(208)}$. Quercetin pre-treatment decreased tunicamycin-induced ER stress marker expression in HUVEC $^{(209)}$. Poly ADP ribose polymerase (PARP), the end point of a number of cell signalling pathways, is known to control many physiological and pathological outcomes and tends to mediate immunity and inflammation ${ }^{(210)}$. In addition, it has been demonstrated that quercetin re-establishes ER homeostasis by reducing caspase- 3 and caspase-dependent PARP cleavage and normalising the antioxidant enzymes SOD1 and catalase (CAT) under ER stress ${ }^{(209)}$. Further, thapsigargininduced ER calcium depletion due to inhibition of the calcium-ATPase has been restored with resveratrol in the endothelium ${ }^{(211)}$, and it also prevented retinal vascular degeneration induced by tunicamycin ${ }^{(212)}$.

\section{Inflammatory pathway}

In addition to the mediators of vasomotor functions, vascular endothelial cells release inflammatory mediators that are forerunners in the initiation, amplification and resolution of the inflammatory response. Endothelial cells are more prone to various stresses including glucose toxicity, which stimulates the secretion of proinflammatory cytokines and adhesion factors ${ }^{(213)}$. Endothelial dysfunction focusing vascular inflammation has been implicated in the induction of vasoconstrictors, adhesion 
molecules, Ang II and ET- $1^{(214)}$. ROS tends to be the competent stimulator of ET-1, which in turn activates NOX and XO, worsening the cellular oxidative stress contributing to vascular remodelling and endothelial dysfunction ${ }^{(215,216)}$.

In addition, hyperglycaemia activates NF- $\kappa \mathrm{B}$, the master regulator and major proinflammatory transcription factor that controls multiple proinflammatory and proatherosclerotic targets in endothelial cells, and thus activates inflammation ${ }^{(217)}$. The regulation of $\mathrm{NF}-\kappa \mathrm{B}$ is primarily associated with the $\mathrm{I} \kappa \mathrm{B}$ family of transcription factor inhibitor proteins, and its phosphorylation implies the most important step in its activation $^{(218)}$. At the downstream, NF- $\kappa \mathrm{B}$ activates the transcription of proinflammatory genes including TNF- $\alpha$, IL-1, IL-8, E-selectin, VCAM-1 and ICAM-1 in vascular endothelial cells, as reviewed by Xiao et al. ${ }^{(219)}$, and it also promotes the expression of MCP-1 and adhesion of leucocyte and monocytes to the endothelial cells, which is followed by their infiltration and differentiation into macrophages under hyperglycaemic conditions $^{(220)}$

It has been well documented that under conditions of insulin resistance and $\mathrm{T} 2 \mathrm{D}$, inflammation has been reflected with an increase in TNF- $\alpha$, IL-6, PAI-1, ET-1 and high-sensitive C-reactive protein relating it to endothelial dysfunction ${ }^{(221)}$. In addition, it has been explicated that NEFA-induced ROS activates NF- $\kappa \mathrm{B}$, inhibitor of kappaB kinase (IKK) $\alpha$ and impairs insulin-stimulated activation of eNOS and $\mathrm{NO}^{\circ}$ production in endothelial cells ${ }^{(222)}$.

Many polyphenolic compounds have been reported to ameloriate endothelial dysfunction by inhibiting inflammatory mediators. A recent study with palmitate-induced insulin resistance model reveals that resveratrol suppressed IKK $\beta$ / NF- $\kappa$ B phosphorylation, TNF- $\alpha$ and IL- 6 production and restored the IRS-1/Akt/eNOS signalling pathway in endothelial cells $^{(139)}$. Resveratrol has been reported to block TNF- $\alpha$-induced activation of NF- $\kappa \mathrm{B}$ in coronary arterial endothelial cells and to inhibit inflammatory mediators ${ }^{(223)}$, exerting its effect through action on (IKK) cascade, thereby attributing to its antioxidant properties.

Ferulic acid combined with astragaloside IV is known to protect vascular endothelial dysfunction in STZ-induced diabetic rats by promoting the release of $\mathrm{NO}^{\bullet}$ and eNOS, and inhibiting the hyper-stimulation of MCP-1, TNF- $\alpha$ and NF- $\kappa \mathrm{B}$ P65 in $\operatorname{aorta}^{(147)}$. The administration of the flavonoids such as EGCG, quercetin and delphinidin increased the bioactivity of $\mathrm{NO}^{\bullet}$ and prevented endothelial cell apoptosis by modulating inflammatory pathways ${ }^{(224)}$. Curcumin inhibits proinflammatory cytokines, TNF- $\alpha$, ICAM-1, NOX2 and cyclo-oxygenase-2 expressions and reduces leucocyte-endothelium interaction in diabetes-induced vascular inflammatory models ${ }^{(225-227)}$. The report of Mahmoud et al. confirmed that quercetin confers protection to diabetes-induced vasoconstriction, leading to low-grade inflammation with concomitant reduction in serum levels of both TNF- $\alpha$, CRP and inhibition of NF- $\kappa \mathrm{B}$ in aorta ${ }^{(228)}$.

In addition, increased adhesion of monocytes to bovine aortic endothelial cells (BAEC) and expression of VCAM-1 in response to TNF- $\alpha$ treatment was reversed by pre-exposure with hesperetin ${ }^{(148)}$. In a clinical study, hesperetin treatment increased flow-mediated dilation with the reduction in circulating inflammatory biomarkers such as CRP, serum amyloid A protein and soluble E-selectin ${ }^{(148)}$. Yamagata et al. reported increased expression of ICAM-1 and VCAM1 in the endothelial cells under exposure to high glucose and TNF- $\alpha$; further, the treatment with apigenin significantly inhibited the expression of adhesion molecules and also IKK $\alpha$ and IKKi, thereby mediating the protection against atherosclerotic vascular diseases ${ }^{(229)}$

The molecular link between the activation of PKC and up-regulation of VCAM-1 expression under hyperglycaemic conditions involving NF- $\kappa$ B activation has been studied ${ }^{(230)}$. EGCG has been reported to inhibit the vascular inflammation in hyperglycaemia by suppression of the $\mathrm{PKC} / \mathrm{NF}-\kappa \mathrm{B}$ signalling pathway, and it also prevented monocyte adhesion in HUVEC cells ${ }^{(231)}$.

MAPK signalling was reported to regulate the highglucose-induced inflammatory cytokines ${ }^{(232)}$. A study with emodin (3-methyl-1, 6, 8-trihydroxyanthraquinone), an anthraquinone in HUVEC, reported the inhibition of glucose-induced phosphorylation of ERK $1 / 2$ and p38 MAPK, thereby protecting the cells against inflammation ${ }^{(233)}$. Brazilin markedly inhibited the high-glucose-induced MAPK/ERK signal transduction pathway, thereby inhibiting the phosphorylation of extracellular signal-regulated kinase and transcription factor $\mathrm{NF}-\kappa \mathrm{B}$ in HUVEC cells ${ }^{(234)}$. The report of Kim et al. ${ }^{(232)}$ demonstrated that hesperidin, naringenin and resveratrol reduced high-glucose-induced ICAM-1 expression via the p38 MAPK signalling pathway, contributing to the inhibition of monocyte adhesion to endothelial cells. In STZ-induced diabetic rats and high-glucose-induced HUVEC cells, $\alpha$-linolenic acid treatment decreased the expression of P-selectin, ICAM-1 and neutrophil adhesion via Akt phosphorylation $^{(150)}$.

In high-glucose-induced vascular inflammation in HUVEC and mouse models, increased vascular permeability, monocyte adhesion, expressions of CAM, formation of ROS and activation of $\mathrm{NF}-\kappa \mathrm{B}$, with induced expressions of MCP-1 and IL-8, were ameliorated not only by emodin-6-O- $\beta$-D-glucoside ${ }^{(235)}$ but also by other polyphenols such as fisetin, orientin and naringin model, thereby reducing diabetic complications and atherosclerosis $^{(236-238)}$. A recent study with three structurally related polyphenols such as baicalin, baicalein and wogonin inhibited endothelial cell barrier disruption, suggesting its protection against vascular inflammatory diseases ${ }^{(239)}$. Chronic resveratrol treatment in T2D rats showed a vasoprotective effect through the inhibition of inflammation mediators such as IL- $1 \beta$ and IL-6, decreasing the circulating vWF levels, recovered vascular permeability in both carotid artery and thoracic aorta. In addition, resveratrol showed an inhibitory effect against $\mathrm{NF}-\kappa \mathrm{B}$ p 65 , proinflammatory mediators including TNF- $\alpha$, ICAM-1 and MCP-1 in endothelial cell lines ${ }^{(240)}$.

The protective effect of genistein was proven in the human aortic endothelial cells under exposure to high glucose by its inhibitory action on monocytes, and suppression of MCP-1 and IL- $8^{(241)}$. The combination of quercetin, EGCG and curcumin attenuated high-glucose-induced membrane fluidity and transmembrane potential of HUVEC cells by reducing the AGE products formed and limiting the release of pro-inflammatory 
Table 1. The molecular mechanism of polyphenol antioxidants in modulating endothelial dysfunction under diabetes

\begin{tabular}{|c|c|c|c|c|c|}
\hline SI. no. & Compounds & Type/systematic name/functional group & Mechanism of action & Experimental model & References \\
\hline 1 & $a$-Linolenic acid & $\begin{array}{l}\text { Carboxylic acid/(9Z,12Z,15Z)-octadeca- } \\
\text { 9,12,15-trienoic acid }\end{array}$ & $\begin{array}{l}\text { Increased phosphorylation of Akt at Ser }{ }^{437} \text { and } \mathrm{Thr}^{308} \\
\text { Reduced TNF- } a \text {-stimulated phosphorylation of NF-kB's inhibitory subunit, } \\
\text { IKBa } \\
\text { Enhanced eNOS activity, inhibited iNOS, NADPH oxidase expression and } \\
\text { ONOO- production } \\
\text { Decreased the expression of P-selectin, ICAM-1 and neutrophil adhesion }\end{array}$ & In vitro, In vivo & (150) \\
\hline 2 & Apigenin & $\begin{array}{l}\text { Flavone/5,7-dihydroxy-2-(4-hydroxyphenyl) } \\
\text { chromen-4-one/5-OH, 7-OH, 4'-OH and a } \\
\mathrm{C}(2)=\mathrm{C}(3) \text { double bond and } \mathrm{C}(4)=\mathrm{O} \\
\text { functionalities }\end{array}$ & Inhibited the expression of adhesion molecules, ICAM-1 and VCAM-1 & In vitro & (229) \\
\hline 3 & $\begin{array}{l}\text { Astragaloside IV and } \\
\text { cycloastragenol }\end{array}$ & - & $\begin{array}{l}\text { Enhanced AMPK phosphorylation } \\
\text { Inhibited TXNIP/NLRP3 inflammasome activation and attenuated ER } \\
\text { stress-induced IRE1 } a \text { phosphorylation }\end{array}$ & In vitro & (205) \\
\hline 4 & Baicalin & $\begin{array}{l}\text { Flavone/(2S,3S,4S,5R,6S)-6-(5,6-dihydroxy-4- } \\
\text { oxo-2-phenylchromen-7-yl)oxy-3,4,5- } \\
\text { trihydroxyoxane-2-carboxylic acid/5,6,7-OH, } \\
\text { ortho-dihydroxyl group in ring A }\end{array}$ & $\begin{array}{l}\text { Decreased vascular permeability, NF-kB, cell adhesion molecules and } \\
\text { prevented monocyte adhesion }\end{array}$ & In vitro, In vivo & (239) \\
\hline 5 & Baicalein & $\begin{array}{l}\text { Flavone/5,6,7-trihydroxy-2-phenylchromen-4- } \\
\text { one/5,6,7-OH }\end{array}$ & $\begin{array}{l}\text { Decreased vascular permeability, NF-kB, cell adhesion molecules and } \\
\text { prevented monocyte adhesion }\end{array}$ & In vitro, In vivo & (239) \\
\hline 6 & Berberine & $\begin{array}{l}\text { Isoquinoline alkaloid/5,6-dihydro-9,10- } \\
\text { dimethoxybenzo[g]-1,3-benzodioxolo[5,6-a] } \\
\text { quinolizinium }\end{array}$ & $\begin{array}{l}\text { Activated AMPK, enhanced phosphorylation of eNOS at Ser }{ }^{1177} \text { and } \\
\text { promoted the association of eNOS with HSP90, thereby increasing } \\
\text { NO॰ production } \\
\text { Reduced NF-KB activation, expression of adhesion molecules and } \\
\text { suppressed THP1 monocytes adhesion }\end{array}$ & In vitro, Ex vivo & $(154,155)$ \\
\hline 7 & Brazilin & $\begin{array}{l}\text { Red pigment/(6aS,11bR)-7,11b-dihydro- } 6 \mathrm{H}- \\
\text { indeno[2,1-c]chromene-3,6a,9,10-tetrol }\end{array}$ & $\begin{array}{l}\text { Increased the phosphorylation of eNOS and ERK } \\
\text { Decreased the expression of cell adhesion molecules and NF-kB }\end{array}$ & In vitro & (234) \\
\hline 8 & Catechin hydrate & $\begin{array}{l}\text { Flavanols/(2R,3S)-2-(3,4-dihydroxyphenyl)-3,4- } \\
\text { dihydro-2H-chromene-3,5,7-triol;hydrate/ } \\
3,5,7,3^{\prime}, 4^{\prime}-\mathrm{OH}\end{array}$ & Activated PI3K and eNOS, increased the generation of $\mathrm{NO}^{\circ}$ & In vivo & (151) \\
\hline 9 & Chlorogenic acid & $\begin{array}{l}\text { Phenolic acid-hydroxycinnamic acids/ } \\
\text { (1S,3R,4R,5R)-3-[(E)-3-(3,4- } \\
\text { dihydroxyphenyl)prop-2-enoyl]oxy-1,4,5- } \\
\text { trihydroxycyclohexane-1-carboxylic acid/3,4- } \\
\text { OH,orthodiphenolic functionalities }\end{array}$ & Decreased VEGF levels in diabetic retinopathy & In vivo & (167) \\
\hline \multirow[t]{7}{*}{10} & \multirow[t]{7}{*}{ Curcumin } & \multirow{7}{*}{$\begin{array}{l}\text { Curcuminoids/(1E,6E)-1,7-bis(4-hydroxy-3- } \\
\text { methoxyphenyl)hepta-1,6-diene-3,5-dione/ } \\
\text { 8,8'-OH, 7,7'-OCH3 O-methoxyphenol group } \\
\text { and methylenic hydrogen }\end{array}$} & $\begin{array}{l}\text { Inhibited the PKC } \beta \text { II translocation induced by VEGF in human retinal } \\
\text { endothelial cells }\end{array}$ & In vitro & (169) \\
\hline & & & $\begin{array}{l}\text { Increased GSH levels } \\
\text { Inhibited the levels of IL-1 } \beta \text {, VEGF and NF-kB }\end{array}$ & In vivo & (165) \\
\hline & & & Inhibited expression of VEGF in diabetic retina and kidney & In vivo & $(164,166)$ \\
\hline & & & $\begin{array}{l}\text { Increased VEGF and transforming growth factor } \beta 1 \text {, hypoxia-inducible } \\
\text { growth factor-1 } 1 a \text {, stromal cell-derived growth factor- } 1 a \text {, and HO-1 } \\
\text { expression in diabetic wound healing }\end{array}$ & In vivo & (260) \\
\hline & & & Reduced leucocyte-endothelium interaction, inhibited ICAM-1 and NOX2 & In vivo & (225) \\
\hline & & & $\begin{array}{l}\text { Increased GSH, SOD and CAT levels } \\
\text { Reduced the level of TNF- } a\end{array}$ & In vivo & (226) \\
\hline & & & $\begin{array}{l}\text { Suppressed COX-2 and NF-kB levels, inhibited PKC- } \beta \text { II and improved } \\
\text { the ratio of prostanoid products PGI2:TXA2 }\end{array}$ & In vivo & (227) \\
\hline 11 & Daidzein & $\begin{array}{l}\text { Isoflavone/7-hydroxy-3-(4-hydroxyphenyl) } \\
\text { chromen-4-one/7,4'-OH }\end{array}$ & $\begin{array}{l}\text { Activated NO } \\
\text { Reversed the increased MDA content and activity of SOD }\end{array}$ & Ex vivo & (146) \\
\hline 12 & $\begin{array}{l}\text { Emodin-6-O- } \beta \text {-D- } \\
\text { glucoside }\end{array}$ & Anthraquinones & $\begin{array}{l}\text { Decreased vascular permeability, expressions of adhesion molecules, } \\
\text { monocyte adhesion and NF-kB }\end{array}$ & In vitro, In vivo & (235) \\
\hline
\end{tabular}


Table 1. Continued

\begin{tabular}{|c|c|c|c|c|c|}
\hline Sl. no. & Compounds & Type/systematic name/functional group & Mechanism of action & Experimental model & References \\
\hline 13 & Emodin & $\begin{array}{l}\text { Anthraquinones/1,3,8-trihydroxy-6- } \\
\text { methylanthracene-9,10-dione/1,6,8-OH, 3- } \mathrm{CH}_{3}\end{array}$ & Inhibited the phosphorylation of ERK $1 / 2$ and p38 MAPK & In vitro & (233) \\
\hline \multirow[t]{6}{*}{14} & \multirow{6}{*}{$\begin{array}{l}\text { Epigallocatechin-3- } \\
\text { gallate }\end{array}$} & \multirow{6}{*}{$\begin{array}{l}\text { Flavanols/[(2R,3R)-5,7-dihydroxy-2-(3,4,5- } \\
\text { trihydroxyphenyl)-3,4-dihydro-2H-chromen-3-yl] } \\
\text { 3,4,5-trihydroxybenzoate/phenolic hydroxyl } \\
\text { groups on rings B and D,3-OG (G = galloyl) }\end{array}$} & Increased the phosphorylation of eNOS, IRS-1 and Akt & In vivo & (149) \\
\hline & & & & In vitro, In vivo & (152) \\
\hline & & & Decreased NF-kB and phospho-IkBa expression & In vitro & (231) \\
\hline & & & $\begin{array}{l}\text { Inhibited PKC, VCAM-1 expression and the adhesion of THP-1 } \\
\text { monocytes }\end{array}$ & & \\
\hline & & & Reduced the nuclear translocation of NF-kB p65 & \multirow{2}{*}{ In vitro, In vivo } & \multirow[t]{2}{*}{ (261) } \\
\hline & & & $\begin{array}{l}\text { Decreased the levels of MCP-1, serum VCAM- } 1 \text {, ICAM-1 levels and } \\
\text { prevented monocyte adhesion }\end{array}$ & & \\
\hline 15 & Eriodictyol & $\begin{array}{l}\text { Flavanone/(2S)-2-(3,4-dihydroxyphenyl)-5,7- } \\
\text { dihydroxy-2,3-dihydrochromen-4-one/ } \\
5,7,3^{\prime}, 4^{\prime}-\mathrm{OH}\end{array}$ & Enhanced ERK/Nrf2/ARE-dependent HO-1 expression & In vitro & (256) \\
\hline 16 & Fisetin & $\begin{array}{l}\text { Flavone/2-(3,4-dihydroxyphenyl)-3,7- } \\
\text { dihydroxychromen-4-one/3, 3', 4'-OH, double } \\
\text { bond between C-2 and C-3 conjugated with } \\
\text { 4-oxo group }\end{array}$ & $\begin{array}{l}\text { Decreased the vascular permeability, expressions of adhesion molecules, } \\
\text { monocyte adhesion and activation of NF-kB } \\
\text { Decreased the number of THP-1 monocytes adhesion }\end{array}$ & In vitro, In vivo & (237) \\
\hline 17 & Genistein & $\begin{array}{l}\text { Isoflavones/5,7-dihydroxy-3-(4-hydroxyphenyl) } \\
\text { chromen-4-one/5,7,4'-OH and a } \mathrm{C}(2)=\mathrm{C}(3) \\
\text { double bond and } \mathrm{C}(4)=\mathrm{O} \text { functionalities }\end{array}$ & $\begin{array}{l}\text { Inhibited monocyte adhesion, and suppressed MCP-1, IL- } 8 \text { and serum } \\
\text { ICAM- } 1 \text { and VCAM- } 1 \text { levels } \\
\text { Exhibited the antiadhesion effect by suppressing monocyte-endothelial } \\
\text { cell interaction mediated through the CAMP/PKA pathway }\end{array}$ & In vitro, In vivo & (241) \\
\hline \multirow[t]{2}{*}{18} & \multirow[t]{2}{*}{ Hesperetin } & \multirow[t]{2}{*}{$\begin{array}{l}\text { Flavanones/(2S)-5,7-dihydroxy-2-(3-hydroxy-4- } \\
\text { methoxyphenyl)-2,3-dihydrochromen-4-one/ } \\
5,7,3^{\prime}-\mathrm{OH}, 4^{\prime}-\mathrm{OCH} 3\end{array}$} & $\begin{array}{l}\text { Stimulated phosphorylation of Src, Akt, AMP kinase, eNOS to produce } \\
\text { NO;, reduced the concentrations of circulating inflammatory } \\
\text { biomarkers such as C-reactive protein, serum amyloid A protein, } \\
\text { soluble E-selectin }\end{array}$ & In vitro, Clinical & \multirow[t]{2}{*}{ (148) } \\
\hline & & & $\begin{array}{l}\text { Reduced the TNF- } a \text {-stimulated expression of VCAM- } 1 \text { and adhesion of } \\
\text { monocytes }\end{array}$ & & \\
\hline \multirow[t]{2}{*}{19} & \multirow[t]{2}{*}{ Ilexgenin A } & \multirow[t]{2}{*}{-} & $\begin{array}{l}\text { Increased eNOS phosphorylation, NO production and } \Delta \psi m \\
\text { Enhanced AMPK phosphorylation, inhibited PERK and IRE1a } \\
\text { phosphorylation }\end{array}$ & In vitro, In vivo, Ex vivo & \multirow[t]{2}{*}{ (204) } \\
\hline & & & Reduced TXNIP induction, IL-6 and VCAM-1 production & & \\
\hline 20 & Mangiferin & $\begin{array}{l}\text { Xanthonoid/1,3,6,7-tetrahydroxy-2- } \\
\text { [(2S,3R,4R,5S,6R)-3,4,5-trihydroxy-6- } \\
\text { (hydroxymethyl)oxan-2-yl]xanthen-9-one/6,7- } \\
\text { dihydroxylated structure (catechol moiety) }\end{array}$ & $\begin{array}{l}\text { Increased AMPK phosphorylation (AMPKa T172), restored the loss in } \\
\text { NO production, } \Delta \Psi m \text { and inhibited ET-1 secretion } \\
\text { Prevented IRE1a phosphorylation, inhibited TXNIP expression and } \\
\text { suppressed NLRP3 inflammasome activation }\end{array}$ & In vitro & (199) \\
\hline 21 & Naringin & $\begin{array}{l}\text { Flavanone/(2S)-7-[(2S,3R,4S,5S,6R)-4,5- } \\
\text { dihydroxy-6-(hydroxymethyl)-3- } \\
\text { [(2S,3R,4R,5R,6S)-3,4,5-trihydroxy-6- } \\
\text { methyloxan-2-yl]oxyoxan-2-yl]oxy-5-hydroxy- } \\
\text { 2-(4-hydroxyphenyl)-2,3-dihydrochromen-4- } \\
\text { one/5,4'-OH, 7-O-rutinose }\end{array}$ & Suppressed the adhesion of THP- 1 monocytes and NF-kB expression & In vitro & (236) \\
\hline 22 & Orientin & $\begin{array}{l}\text { Flavone/2-(3,4-dihydroxyphenyl)-5,7-dihydroxy- } \\
\text { 8-[(2S,3R,4R,5S,6R)-3,4,5-trihydroxy-6- } \\
\text { (hydroxymethyl)oxan-2-yl]chromen-4-one/ } \\
\text { O-phenolic hydroxyl in the B ring }\end{array}$ & $\begin{array}{l}\text { Decreased the vascular permeability, expression of cell adhesion } \\
\text { molecules, monocyte adhesion and activation of NF-kB }\end{array}$ & In vitro, In vivo & (238) \\
\hline 23 & Paeonol & $\begin{array}{l}\text { Phenol/1-(2-hydroxy-4-methoxyphenyl) } \\
\text { ethanone }\end{array}$ & $\begin{array}{l}\text { Decreased VEGF and PDGF-B } \\
\text { Reduced LDH release }\end{array}$ & In vitro & (170) \\
\hline 24 & Propyl gallate & $\begin{array}{l}\text { Ester (condensation of gallic acid and } \\
\text { propanol)/propyl 3,4,5-trihydroxybenzoate/ } \\
\text { orthodiphenolic functionalities }\end{array}$ & $\begin{array}{l}\text { Restored eNOS activity and recovered VEGF-NO^ axis } \\
\text { Restored SOD, CAT, GSH-Px levels and decreased MDA levels }\end{array}$ & In vivo & $(144,145)$ \\
\hline
\end{tabular}


Table 1. Continued

\begin{tabular}{|c|c|c|c|c|c|}
\hline SI. no. & Compounds & Type/systematic name/functional group & Mechanism of action & Experimental model & References \\
\hline \multirow[t]{4}{*}{25} & \multirow[t]{4}{*}{ Quercetin } & \multirow{4}{*}{$\begin{array}{l}\text { Flavonols/2-(3,4-dihydroxyphenyl)-3,5,7- } \\
\text { trihydroxychromen-4-one/meta-dihydroxyl group } \\
\text { in ring } \mathrm{A} \text { (on } 5 \text { and } 7 \text { position) and an ortho- } \\
\text { dihydroxyl group in ring B (on 3', 4' position) }\end{array}$} & $\begin{array}{l}\text { Increased eNOS phosphorylation, NO` production and cGMP levels with } \\
\text { enhanced SIRT1 expression }\end{array}$ & In vitro & (142) \\
\hline & & & $\begin{array}{l}\text { Increased the phosphorylation of eNOS at Ser1179 and also the } \\
\text { expressions of PKA, Akt and ERK1/2 }\end{array}$ & In vitro, Ex vivo & (143) \\
\hline & & & $\begin{array}{l}\text { Increased the levels of antioxidant enzymes, SOD and CAT } \\
\text { Reduced the expressions of GRP78 and CHOP }\end{array}$ & In vitro & (209) \\
\hline & & & $\begin{array}{l}\text { Reduced the serum level of both TNF- } a \text { and CRP, inhibited NF-kB } \\
\text { expression }\end{array}$ & In vivo & (228) \\
\hline \multirow[t]{8}{*}{26} & \multirow[t]{8}{*}{ Resveratrol } & \multirow[t]{8}{*}{$\begin{array}{l}\text { Stilbenes/5-[(E)-2-(4-hydroxyphenyl)ethenyl] } \\
\text { benzene-1,3-diol/3,5,4'-OH and acidic para- } \\
\text { 4'-OH group. Stilbenic double bond }\end{array}$} & $\begin{array}{l}\text { Increased IRS-1/Akt/eNOS signalling and also regulated AMPK and SIRT1 } \\
\text { Decreased the secretion of endothelin-1, plasminogen activator inhibitor-1 and } \\
\text { suppressed IKK } \beta / N F-k B \text { phosphorylation }\end{array}$ & In vitro, In vivo & (139) \\
\hline & & & Increased eNOS protein expression & In vivo & (140) \\
\hline & & & $\begin{array}{l}\text { Down-regulated VEGF and Flk-1 in diabetic nephropathy } \\
\text { Increased transcription level of Ang-2 mRNA }\end{array}$ & In vivo & (262) \\
\hline & & & $\begin{array}{l}\text { Down-regulated the expressions of VEGF, VEGF receptor-2 expression, } \\
\text { caveolin } 1 \text { and suppressed hyperpermeability }\end{array}$ & In vitro & (172) \\
\hline & & & Enhanced cytosolic $\mathrm{Ca}$ increase & Ex vivo & (211) \\
\hline & & & $\begin{array}{l}\text { Inhibited monocyte adhesion and expressions of iNOS, IL- } 6 \text { and adhesion } \\
\text { molecules }\end{array}$ & In vitro & (223) \\
\hline & & & $\begin{array}{l}\text { Inhibited inflammatory mediators such as IL-1 } 1 \beta \text {, IL-6, NF-KB p65, TNF- } a \text {, } \\
\text { ICAM-1, MCP-1 and also decreased the circulating VWF levels }\end{array}$ & In vivo & (240) \\
\hline & & & $\begin{array}{l}\text { Increased the transcriptional activity of Nrf2 and up-regulated Nrf2/ARE- } \\
\text { driven genes such as NAD }(\mathrm{P}) \mathrm{H} \text { : quinone oxidoreductase } 1 \text {, } \\
\gamma \text {-qlutamylcysteine synthetase and } \mathrm{HO}-1\end{array}$ & In vitro, In vivo & (254) \\
\hline 27 & Scutellarein & $\begin{array}{l}\text { Flavone/5,6,7-trihydroxy-2-(4-hydroxyphenyl) } \\
\text { chromen-4-one }\end{array}$ & $\begin{array}{l}\text { Inhibited cell proliferation via down-regulating VEGF expression in } \\
\text { diabetic retinopathy }\end{array}$ & In vitro & (171) \\
\hline 28 & Silibinin & $\begin{array}{l}\text { Flavonolignans/(2R,3R)-3,5,7-trihydroxy-2- } \\
\text { [(2R,3R)-3-(4-hydroxy-3-methoxyphenyl)-2- } \\
\text { (hydroxymethyl)-2,3-dihydro-1,4- } \\
\text { benzodioxin-6-yl]-2,3-dihydrochromen-4-one/ } \\
\text { OH at C5 and C3 in addition to the carbonyl } \\
\text { group at C4 and two carboxylate groups }\end{array}$ & Reduced circulating and vascular ADMA levels & In vivo & (153) \\
\hline \multirow[t]{3}{*}{29} & \multirow[t]{3}{*}{ Sulforaphane } & \multirow[t]{3}{*}{$\begin{array}{l}\text { Isothiocyanate/1-isothiocyanato-4- } \\
\text { methylsulfinylbutane }\end{array}$} & $\begin{array}{l}\text { Promoted nuclear localisation of Nrf2 and increased the expression of } \\
\text { GSH synthesis enzymes, GCLC and GCLM }\end{array}$ & In vivo & (255) \\
\hline & & & $\begin{array}{l}\text { Up-regulated HO-1 expression through the ERK/Nrf2/ARE-dependent } \\
\text { pathway, prevented activation of hexosamine and PKC pathways and } \\
\text { formation of methylglyoxal }\end{array}$ & In vitro & (258) \\
\hline & & & $\begin{array}{l}\text { Increased the expression of Nrf2 and its downstream HO-1 and NQO-1 } \\
\text { Reduced IKB kinase phosphorylation, NF-kB, iNOS and COX-2 } \\
\text { expression, and the levels of TNF- } a \text { and IL-6 }\end{array}$ & In vitro, In vivo & (259) \\
\hline 30 & Wogonin & $\begin{array}{l}\text { Flavone/5,7-dihydroxy-8-methoxy-2- } \\
\text { phenylchromen-4-one/C-2,3 double bond } \\
\text { and the positions of the phenolic } \\
\text { polyhydroxyl groups on A-ring, intramolecular } \\
\text { hydrogen bond between } 5-\mathrm{OH} \text { and } 4-\mathrm{CO}\end{array}$ & $\begin{array}{l}\text { Decreased vascular permeability, NF- } k \mathrm{~B} \text {, cell adhesion molecules and } \\
\text { monocyte adhesion }\end{array}$ & In vitro, In vivo & (239) \\
\hline
\end{tabular}

eNOS, endothelial nitric oxide synthase; ICAM-1, intercellular adhesion molecule 1; VCAM-1, vascular cell adhesion molecule 1; AMPK, AMP-activated protein kinase; TXNIP, thioredoxin-interacting protein; NLRP3, NOD-like receptor protein 3; ER, endoplasmic reticulum; IRE1, inositol-requiring enzyme 1; HSP90, heat shock protein 90; NO; nitric oxide; VEGF, vascular endothelial growth factor; PKC, protein kinase C; NOX2, NADPH oxidase isoform 2; SOD, superoxide dismutase; CAT, catalase; COX-2, cyclo-oxygenase 2; IRS-1, insulin receptor substrate 1; DDAH, dimethylarginine dimethylaminohydrolase; ADMA, asymmetric dimethylarginine; MCP-1, monocyte chemoattractant protein1; Nrf2, nuclear factor-E2-related factor 2; ARE, antioxidant response elements; ET-1, endothelin-1; PERK, protein kinase RNA-like endoplasmic reticulum kinase; PDGF-B, platelet-derived growth factor B; cGMP, cyclic GMP; CHOP, C/ERB homologous protein; SIRT1, sirtuin 1; Ang 2, angiopoietin 2; HO-1, heme oxygenase-1; cAMP, cyclic AMP; vWF, von Willebrand factor; AMPK, AMP-activated protein kinase; MDA, malondialdehyde; THP-1, engineered human
reporter monocytes; iNOS, inducible nitric oxide synthase; GCLc, glutamate-cysteine ligase, catalytic subunit; GCLM, glutamate-cysteine ligase, modifier subunit; GSH-Px, glutathione peroxidase. 
factors such as MCP-1, thereby preventing chronic inflammation $^{(242)}$

\section{Nuclear factor-E2-related factor 2-mediated antioxidant pathway}

$\mathrm{Nrf} 2$ is a transcription factor that is perhaps the most prominent cellular defence mechanism against oxidative stress. Under basal conditions, Nrf2 is primarily localised in the cytoskeleton as a complex with Kelch-like erythroid cell-derived protein with cap (n) collar homology [ECH]-associated protein 1 (Keap1). Oxidative stress causes the dissociation of Nrf2 from Keap1 and is found to bind with antioxidant response elements (ARE) in the nucleus, promoting the transcription of a number of endogenous protective genes including antioxidant genes, phase II detoxification enzyme genes and molecular chaperones. Nrf2 endorses cellular redox homeostasis via its downstream activation of several intracellular antioxidants such as $\gamma$-glutamine cysteine synthase, SOD, CAT, glutathione reductase, glutathione peroxidase, peroxiredoxin and thioredoxin reductase, and phase II detoxifying enzymes such as $\mathrm{HO}-1$, glutathione S-transferase, $\mathrm{NAD}(\mathrm{P}) \mathrm{H}$ quinone oxidoreductase 1 ; and also proteins involved in detoxifying xenobiotics and neutralising $\operatorname{ROS}^{(243,244)}$.

Several protein kinases such as MAPK, PKC, PI3K, glycogen synthase kinase 3 beta (GSK3b) and casein kinase 2 are reported to be involved in Nrf2 regulation, playing a role in its phosphorylation $^{(245)}$. In addition, the cross talk between Nrf2 and ATF6 has been demonstrated in endothelial cells ${ }^{(246)}$. The Nrf2/ARE pathway regulates DDAH in order to reduce ADMA and PPAR- $\gamma$ to increase eNOS and its phosphorylation ${ }^{(247)}$. Several studies have reported that Nrf2 acts as a defence mechanism against diabetes-mediated complications. Zhong et $a l .^{(248)}$ reported impairment of Nrf2-Keap1 in endothelial cells that were exposed to high glucose and also in retinas from donors with diabetic retinopathy. In vivo models of high-fat-diet $\mathrm{Nrf} 2^{-/-}$and $\mathrm{Nrf} 2^{+/+}$mice explained the increase of vascular ROS in $\mathrm{Nrf2}^{-/-}$than in $\mathrm{Nrf2^{+/+ }}$ mice and the adaptive activation of the Nrf2-ARE pathway confirming the endothelial protection under diabetes ${ }^{(249)}$. It has also reported that patients with diminished Nrf2 activity had a higher incidence of T2D and cardiovascular problems ${ }^{(250)}$. In STZ-induced diabetic Nrf2 knockdown mice, the diminished oxidative defence causes reduced renal function leading to diabetic nephropathy ${ }^{(251)}$. Activation of insulin signalling through the $\mathrm{PI} 3 \mathrm{~K} / \mathrm{Akt} / \mathrm{mTOR}$ (mechanistic target of rapamycin)/Nrf2/GCLc (glutamate-Lcysteine ligase; catalytic subunit) pathway affords significant protection in human brain endothelial cells against hyperglycaemia by maintaining cellular redox balance ${ }^{(252)}$. In addition, the Nrf2 knockout mouse model confirmed the role of Nrf2 in hyperglycaemia-induced ROS production and in cardiomyocytes and renal tissue injury ${ }^{(253)}$. Attention is being drawn to uncover the protective mechanism of polyphenolic compounds against diabetes-mediated endothelial dysfunction via Nrf2 activation.

Resveratrol confers a protective effect against high-glucoseinduced oxidative stress in endothelial cells and vasoprotective effect in high-fat-diet mice, through the Nrf2 pathway ${ }^{(254)}$. Sulforaphane decreases the ROS production and restores myogenic response in $\mathrm{T} 2 \mathrm{D}$ mesenteric arterioles through the Nrf2 pathway ${ }^{(25)}$. HUVEC treated with eriodictyol showed the up-regulation of HO-1 through ERK/Nrf2/ARE-dependent pathways, in which ERK aids in the translocation of Nrf2 in the nucleus for HO-1 activation ${ }^{(256)}$.

Moreover, Nrf2 activation inhibits NF- $\kappa \mathrm{B}$ through reduced ROS-mediated IKK activation and inhibits the degradation of IкB. Interaction between these two pathways maintains the homeostasis, in which oxidative stress causes the imbalance in the Nrf2-NF- $\mathrm{BB}$ axis ${ }^{(257)}$. Sulforaphane also suppressed hyperglycaemia-induced ROS and metabolic dysfunction in human microvascular endothelial cell via Nrf2 activation ${ }^{(258)}$. Sulforaphane has been also reported to enhance Nrf2-mediated antioxidant expression in experimental models of diabetic neuropathy through Nrf2 and NF- $\kappa$ B modulation ${ }^{(259)}$.

The molecular mechanisms of polyphenol antioxidants with emphasis on their potential in improvement of endothelial function are summarised in Table 1.

\section{Conclusion}

Endothelial dysfunction is one of the key contributors to the development of diabetic complications, and it characterised by reduced endothelium-mediated vasorelaxation, impaired fibrinolytic capacity, overproduction of growth factors, increased expression of adhesion molecules and inflammatory genes, excessive generation of free radicals, increased oxidative stress and enhanced permeability of the cell layer. Under hyperglycaemia, the ultrastructure of the extracellular matrix of the endothelial cell tends to alter glucose metabolism and impair insulin signalling, ER stress and inflammation, the major risk factors that contribute to endothelial dysfunction. Numerous therapeutic strategies have been developed for restoring normal endothelial function in diabetic conditions. One such promising approach is the antioxidant therapy; in particular, polyphenols are reported not only to alleviate the status of oxidative stress but also to act on cellular signalling pathways including $\mathrm{NO}^{\bullet}$ signalling, VEGF-mediated angiogenesis, ER stress and Nrf2-antioxidant pathway, thereby preventing the vascular complications in diabetes. Hence, future research needs to focus on clinical acceptance of potent polyphenols along with the risk assessment and safety evaluation.

\section{Acknowledgements}

N. S. acknowledges the Council of Scientific and Industrial Research, New Delhi, India, for the award of Senior Research Fellowship.

The present study was supported by grants from the Indian Council of Medical Research (grant no. 59/57/2011/BMS/TRM), Government of India.

D. V. L. S. and K. M. R. conceived and designed the study. N. S. and E. B. participated in the development of the database and drafted the paper. All the authors read and approved the final version of the manuscript.

The authors declare that there are no conflicts of interest. 


\section{References}

1. Galley HF \& Webster NR (2004) Physiology of the endothelium. Br J Anaesth 93, 105-113.

2. Cersosimo E \& DeFronzo RA (2006) Insulin resistance and endothelial dysfunction: the road map to cardiovascular diseases. Diabetes Metab Res Rev 22, 423-436.

3. Aird WC (2007) Phenotypic heterogeneity of the endothelium: I. Structure, function, and mechanisms. Circ Res 100, 158-173.

4. Rubanyi GM (1991) Endothelium-derived relaxing and contracting factors. J Cell Biochem 46, 27-36.

5. Shimokawa H, Yasutake H, Fujii K, et al. (1996) The importance of the hyperpolarizing mechanism increases as the vessel size decreases in endothelium-dependent relaxations in rat mesenteric circulation. I Cardiovasc Pharmacol 28, 703-711.

6. Rajendran P, Rengarajan T, Thangavel J, et al. (2013) The vascular endothelium and human diseases. Int J Biol Sci 9 , 1057-1069.

7. Chan AK \& Paredes N (2013) The coagulation system in humans. Methods Mol Biol 992, 3-12.

8. Michiels C (2003) Endothelial cell functions. J Cell Physiol 196, 430-443.

9. Verhamme P \& Hoylaerts MF (2006) The pivotal role of the endothelium in haemostasis and thrombosis. Acta Clin Belg 61, 213-219.

10. Patan S (2004) Vasculogenesis and angiogenesis. Cancer Treat Res 117, 3-32.

11. Zachary I (2003) VEGF signalling: integration and multi-tasking in endothelial cell biology. Biochem Soc Trans 31, 1171-1177.

12. Olsson AK, Dimberg A, Kreuger J, et al. (2006) VEGF receptor signalling - in control of vascular function. Nat Rev Mol Cell Biol 7, 359-371.

13. Biegelsen ES \& Loscalzo J (1999) Endothelial function and atherosclerosis. Coron Artery Dis 10, 241-256.

14. Carman CV \& Springer TA (2004) A transmigratory cup in leukocyte diapedesis both through individual vascular endothelial cells and between them. I Cell Biol 167, 377-388.

15. Rahman A, Anwar KN \& Malik AB (2000) Protein kinase C-zeta mediates TNF-alpha-induced ICAM-1 gene transcription in endothelial cells. Am J Physiol Cell Physiol 279. C906-C914.

16. Mestas J \& Ley K (2008) Monocyte-endothelial cell interactions in the development of atherosclerosis. Trends Cardiovasc Med 18, 228-232.

17. Gokce N, Keaney JF Jr, Hunter LM, et al. (2002) Risk stratification for postoperative cardiovascular events via noninvasive assessment of endothelial function: a prospective study. Circulation 105, 1567-1572.

18. Libby P, Ridker PM \& Maseri A (2002) Inflammation and atherosclerosis. Circulation 105, 1135-1143.

19. Wang H, Wang AX, Aylor K, et al. (2013) Nitric oxide directly promotes vascular endothelial insulin transport. Diabetes $\mathbf{6 2}$, 4030-4042.

20. Joshua IG, Zhang Q, Falcone JC, et al. (2005) Mechanisms of endothelial dysfunction with development of type 1 diabetes mellitus: role of insulin and C-peptide. J Cell Biochem 96, 1149-1156.

21. Hamilton SJ, Chew GT \& Watts GF (2007) Therapeutic regulation of endothelial dysfunction in type 2 diabetes mellitus. Diab Vasc Dis Res 4, 89-102.

22. Addabbo F, Montagnani M \& Goligorsky MS (2009) Mitochondria and reactive oxygen species. Hypertension $\mathbf{5 3}$ 885-892.
23. Basha B, Samuel SM, Triggle CR, et al. (2012) Endothelial dysfunction in diabetes mellitus: possible involvement of endoplasmic reticulum stress? Exp Diabetes Res 2012, 481840.

24. De Vriese AS, Verbeuren TJ, Van de Voorde J, et al. (2000) Endothelial dysfunction in diabetes. Br J Pharmacol 130, 963-974.

25. Zanetti M, Stocca A, Dapas B, et al. (2008) Inhibitory effects of fenofibrate on apoptosis and cell proliferation in human endothelial cells in high glucose. J Mol Med (Berl) 86, 185-195.

26. Bucciarelli LG, Pollreisz A, Kebschull M, et al. (2009) Inflammatory stress in primary venous and aortic endothelial cells of type 1 diabetic mice. Diab Vasc Dis Res 6, 249-261.

27. Banumathi E, Sheikpranbabu S, Haribalaganesh R, et al. (2010) PEDF prevents reactive oxygen species generation and retinal endothelial cell damage at high glucose levels. Exp Eye Res 90, 89-96.

28. Wang S, Peng Q, Zhang J, et al. (2008) $\mathrm{Na}+/ \mathrm{H}+$ exchanger is required for hyperglycaemia-induced endothelial dysfunction via calcium-dependent calpain. Cardiovasc Res 80, 255-262.

29. Vanhoutte PM, Shimokawa H, Tang EH, et al. (2009) Endothelial dysfunction and vascular disease. Acta Physiol (Oxf) 196, 193-222.

30. Kubota T, Kubota N, Kumagai H, et al. (2011) Impaired insulin signaling in endothelial cells reduces insulininduced glucose uptake by skeletal muscle. Cell Metab 13, 294-307.

31. Kim JA, Koh KK \& Quon MJ (2005) The union of vascular and metabolic actions of insulin in sickness and in health. Arterioscler Thromb Vasc Biol 25, 889-891.

32. Gogg S, Smith U \& Jansson PA (2009) Increased MAPK activation and impaired insulin signaling in subcutaneous microvascular endothelial cells in type 2 diabetes: the role of endothelin-1. Diabetes 58, 2238-2245.

33. Arcaro G, Cretti A, Balzano S, et al. (2002) Insulin causes endothelial dysfunction in humans: sites and mechanisms. Circulation 105, 576-582.

34. Muniyappa R, Iantorno M \& Quon MJ (2008) An integrated view of insulin resistance and endothelial dysfunction. Endocrinol Metab Clin North Am 37, 685-711, ix-x.

35. Cusi K, Maezono K, Osman A, et al. (2000) Insulin resistance differentially affects the PI 3-kinase- and MAP kinase-mediated signaling in human muscle. $J$ Clin Invest 105, 311-320.

36. Duerrschmidt N, Wippich N, Goettsch W, et al. (2000) Endothelin-1 induces $\mathrm{NAD}(\mathrm{P}) \mathrm{H}$ oxidase in human endothelial cells. Biochem Biophys Res Commun 269, 713-717.

37. Potenza MA, Gagliardi S, Nacci C, et al. (2009) Endothelial dysfunction in diabetes: from mechanisms to therapeutic targets. Curr Med Chem 16, 94-112.

38. Bakker W, Eringa EC, Sipkema P, et al. (2009) Endothelial dysfunction and diabetes: roles of hyperglycemia, impaired insulin signaling and obesity. Cell Tissue Res 335, 165-189.

39. Erdei N, Toth A, Pasztor ET, et al. (2006) High-fat diet-induced reduction in nitric oxide-dependent arteriolar dilation in rats: role of xanthine oxidase-derived superoxide anion. Am I Physiol Heart Circ Physiol 291, H2107-H2115.

40. Okon EB, Chung AW, Rauniyar P, et al. (2005) Compromised arterial function in human type 2 diabetic patients. Diabetes 54, 2415-2423.

41. Okon EB, Szado T, Laher I, et al. (2003) Augmented contractile response of vascular smooth muscle in a diabetic mouse model. J Vasc Res 40, 520-530. 
42. Bagi Z, Koller A \& Kaley G (2003) Superoxide-NO interaction decreases flow- and agonist-induced dilations of coronary arterioles in type 2 diabetes mellitus. $\mathrm{Am} \mathrm{J}$ Physiol Heart Circ Physiol 285, H1404-H1410.

43. Shin HK, Kim YK, Kim KY, et al. (2004) Remnant lipoprotein particles induce apoptosis in endothelial cells by $\mathrm{NAD}(\mathrm{P}) \mathrm{H}$ oxidase-mediated production of superoxide and cytokines via lectin-like oxidized low-density lipoprotein receptor-1 activation: prevention by cilostazol. Circulation 109, 1022-1028.

44. Lenaz G, Bovina C, D'Aurelio M, et al. (2002) Role of mitochondria in oxidative stress and aging. Ann N Y Acad Sci 959, 199-213.

45. Pangare M \& Makino A (2012) Mitochondrial function in vascular endothelial cell in diabetes. J Smooth Muscle Res $\mathbf{4 8}$, $1-26$.

46. Davidson SM \& Duchen MR (2007) Endothelial mitochondria: contributing to vascular function and disease. Circ Res 100, 1128-1141.

47. Makino A, Scott BT \& Dillmann WH (2010) Mitochondrial fragmentation and superoxide anion production in coronary endothelial cells from a mouse model of type 1 diabetes. Diabetologia 53, 1783-1794.

48. Griendling KK \& FitzGerald GA (2003) Oxidative stress and cardiovascular injury: part II: animal and human studies. Circulation 108, 2034-2040.

49. Sugamura K \& Keaney JF Jr (2011) Reactive oxygen species in cardiovascular disease. Free Radic Biol Med 51, 978-992.

50. Paravicini TM \& Touyz RM (2008) NADPH oxidases, reactive oxygen species, and hypertension: clinical implications and therapeutic possibilities. Diabetes Care 31, Suppl. 2, S170-S180.

51. San Martin A, Du P, Dikalova A, et al. (2007) Reactive oxygen species-selective regulation of aortic inflammatory gene expression in type 2 diabetes. Am J Physiol Heart Circ Physiol 292, H2073-H2082.

52. Clemmer JS, Xiang L, Lu S, et al. (2016) Hyperglycemiamediated oxidative stress increases pulmonary vascular permeability. Microcirculation 23, 221-229.

53. Matsumoto S, Koshiishi I, Inoguchi T, et al. (2003) Confirmation of superoxide generation via xanthine oxidase in streptozotocin-induced diabetic mice. Free Radic Res 37, $767-772$

54. Butler R, Morris AD, Belch JJ, et al. (2000) Allopurinol normalizes endothelial dysfunction in type 2 diabetics with mild hypertension. Hypertension 35, 746-751.

55. Inkster ME, Cotter MA \& Cameron NE (2007) Treatment with the xanthine oxidase inhibitor, allopurinol, improves nerve and vascular function in diabetic rats. Eur J Pharmacol 561, 63-71.

56. Forstermann U \& Munzel T (2006) Endothelial nitric oxide synthase in vascular disease: from marvel to menace. Circulation 113, 1708-1714.

57. Felaco M, Grilli A, De Lutiis MA, et al. (2001) Endothelial nitric oxide synthase (eNOS) expression and localization in healthy and diabetic rat hearts. Ann Clin Lab Sci 31, 179-186.

58. Taddei S, Ghiadoni L, Virdis A, et al. (2003) Mechanisms of endothelial dysfunction: clinical significance and preventive non-pharmacological therapeutic strategies. Curr Pharm Des 9, 2385-2402.

59. Heitzer T, Schlinzig T, Krohn K, et al. (2001) Endothelial dysfunction, oxidative stress, and risk of cardiovascular events in patients with coronary artery disease. Circulation 104, 2673-2678.

60. Heitzer T, Krohn K, Albers S, et al. (2000) Tetrahydrobiopterin improves endothelium-dependent vasodilation by increasing nitric oxide activity in patients with type II diabetes mellitus. Diabetologia 43, 1435-1438.

61. Francis SH, Busch JL, Corbin JD, et al. (2010) cGMPdependent protein kinases and cGMP phosphodiesterases in nitric oxide and cGMP action. Pharmacol Rev 62, 525-563.

62. Williams IL, Wheatcroft SB, Shah AM, et al. (2002) Obesity, atherosclerosis and the vascular endothelium: mechanisms of reduced nitric oxide bioavailability in obese humans. Int $J$ Obes Relat Metab Disord 26, 754-764.

63. Shi Y \& Vanhoutte PM (2009) Reactive oxygen-derived free radicals are key to the endothelial dysfunction of diabetes. J Diabetes 1, 151-162.

64. Raman CS, Li H, Martasek P, et al. (1998) Crystal structure of constitutive endothelial nitric oxide synthase: a paradigm for pterin function involving a novel metal center. Cell $\mathbf{9 5}$, 939-950.

65. Hodnett BL \& Hester RL (2007) Regulation of muscle blood flow in obesity. Microcirculation 14, 273-288.

66. Hink U, Li H, Mollnau H, et al. (2001) Mechanisms underlying endothelial dysfunction in diabetes mellitus. Circ Res 88, E14-E22.

67. Lin KY, Ito A, Asagami T, et al. (2002) Impaired nitric oxide synthase pathway in diabetes mellitus: role of asymmetric dimethylarginine and dimethylarginine dimethylaminohydrolase. Circulation 106, 987-992.

68. Munzel T, Daiber A, Ullrich V, et al. (2005) Vascular consequences of endothelial nitric oxide synthase uncoupling for the activity and expression of the soluble guanylyl cyclase and the cGMP-dependent protein kinase. Arterioscler Thromb Vasc Biol 25, 1551-1557.

69. Lajer M, Tarnow L, Jorsal A, et al. (2008) Plasma concentration of asymmetric dimethylarginine (ADMA) predicts cardiovascular morbidity and mortality in type 1 diabetic patients with diabetic nephropathy. Diabetes Care 31, 747-752.

70. Krzyzanowska K, Mittermayer F, Wolzt M, et al. (2007) Asymmetric dimethylarginine predicts cardiovascular events in patients with type 2 diabetes. Diabetes Care 30, 1834-1839.

71. Schulz E, Jansen T, Wenzel P, et al. (2008) Nitric oxide, tetrahydrobiopterin, oxidative stress, and endothelial dysfunction in hypertension. Antioxid Redox Signal 10, $1115-1126$.

72. Sheikh-Ali M, Sultan S, Alamir AR, et al. (2010) Hyperglycemia-induced endoplasmic reticulum stress in endothelial cells. Nutrition 26, 1146-1150.

73. Nakagawa T, Zhu H, Morishima N, et al. (2000) Caspase-12 mediates endoplasmic-reticulum-specific apoptosis and cytotoxicity by amyloid-beta. Nature $\mathbf{4 0 3}, 98-103$.

74. Nishitoh H, Matsuzawa A, Tobiume K, et al. (2002) ASK1 is essential for endoplasmic reticulum stress-induced neuronal cell death triggered by expanded polyglutamine repeats. Genes Dev 16, 1345-1355.

75. Ma Y, Brewer JW, Diehl JA, et al. (2002) Two distinct stress signaling pathways converge upon the $\mathrm{CHOP}$ promoter during the mammalian unfolded protein response. J Mol Biol 318, 1351-1365.

76. Ozcan U, Cao Q, Yilmaz E, et al. (2004) Endoplasmic reticulum stress links obesity, insulin action, and type 2 diabetes. Science 306, 457-461.

77. Beleznai T \& Bagi Z (2012) Activation of hexosamine pathway impairs nitric oxide (NO)-dependent arteriolar dilations by increased protein O-GlcNAcylation. Vascul Pharmacol 56, 115-121.

78. Luo B, Soesanto Y \& McClain DA (2008) Protein modification by O-linked GlcNAc reduces angiogenesis by 
inhibiting Akt activity in endothelial cells. Arterioscler Thromb Vasc Biol 28, 651-657.

79. Scallan JP, Hill MA \& Davis MJ (2015) Lymphatic vascular integrity is disrupted in type 2 diabetes due to impaired nitric oxide signalling. Cardiovasc Res 107, 89-97.

80. Scherrer U, Randin D, Vollenweider P, et al. (1994) Nitric oxide release accounts for insulin's vascular effects in humans. J Clin Invest 94, 2511-2515.

81. Baron AD, Steinberg H, Brechtel G, et al. (1994) Skeletal muscle blood flow independently modulates insulin-mediated glucose uptake. Am J Physiol 266, E248-E253.

82. Laine H, Sundell J, Nuutila P, et al. (2004) Insulin induced increase in coronary flow reserve is abolished by dexamethasone in young men with uncomplicated type 1 diabetes. Heart 90, 270-276.

83. Iozzo P, Chareonthaitawee P, Rimoldi O, et al. (2002) Mismatch between insulin-mediated glucose uptake and blood flow in the heart of patients with type II diabetes. Diabetologia 45, 1404-1409.

84. Lambadiari V, Triantafyllou K \& Dimitriadis GD (2015) Insulin action in muscle and adipose tissue in type 2 diabetes: the significance of blood flow. World J Diabetes $\mathbf{6}$, 626-633.

85. Ardilouze JL, Sotornik R, Dennis LA, et al. (2012) Failure to increase postprandial blood flow in subcutaneous adipose tissue is associated with tissue resistance to adrenergic stimulation. Diabetes Metab 38, 27-33.

86. Langille BL \& Adamson SL (1981) Relationship between blood flow direction and endothelial cell orientation at arterial branch sites in rabbits and mice. Circ Res 48, 481-488.

87. Popov D (2010) Endothelial cell dysfunction in hyperglycemia: phenotypic change, intracellular signaling modification, ultrastructural alteration, and potential clinical outcomes. Int J Diabetes Mellit 2, 189-195.

88. Dokken BB (2008) The pathophysiology of cardiovascular disease and diabetes: beyond blood pressure and lipids. Diabetes Spectr 21, 160-165.

89. Simionescu M (2007) Implications of early structural-functional changes in the endothelium for vascular disease. Arterioscler Thromb Vasc Biol 27, 266-274.

90. Mather KJ, Verma S \& Anderson TJ (2001) Improved endothelial function with metformin in type 2 diabetes mellitus. J Am Coll Cardiol 37, 1344-1350.

91. de Jager J, Kooy A, Schalkwijk C, et al. (2014) Long-term effects of metformin on endothelial function in type 2 diabetes: a randomized controlled trial. J Intern Med 275, 59-70.

92. Pratley RE \& Gilbert M (2008) Targeting incretins in type 2 diabetes: role of GLP-1 receptor agonists and DPP-4 inhibitors. Rev Diabet Stud 5, 73-94.

93. Koska J, Sands M, Burciu C, et al. (2015) Exenatide protects against glucose- and lipid-induced endothelial dysfunction: evidence for direct vasodilation effect of GLP-1 receptor agonists in humans. Diabetes 64, 2624-2635.

94. Torimoto K, Okada Y, Mori H, et al. (2015) Effects of exenatide on postprandial vascular endothelial dysfunction in type 2 diabetes mellitus. Cardiovasc Diabetol 14, 25.

95. Thompson CS (2013) Diabetic nephropathy: treatment with phosphodiesterase type 5 inhibitors. World J Diabetes 4. 124-129.

96. Kuno Y, Iyoda M, Shibata T, et al. (2011) Sildenafil, a phosphodiesterase type 5 inhibitor, attenuates diabetic nephropathy in non-insulin-dependent Otsuka Long-Evans Tokushima Fatty rats. Br J Pharmacol 162, 1389-1400.

97. Matsubara J, Sugiyama S, Sugamura K, et al. (2012) A dipeptidyl peptidase-4 inhibitor, des-fluoro-sitagliptin, improves endothelial function and reduces atherosclerotic lesion formation in apolipoprotein E-deficient mice. I Am Coll Cardiol 59, 265-276.

98. van Poppel PC, Netea MG, Smits P, et al. (2011) Vildagliptin improves endothelium-dependent vasodilatation in type 2 diabetes. Diabetes Care 34, 2072-2077.

99. Rieg T, Masuda T, Gerasimova M, et al. (2014) Increase in SGLT1-mediated transport explains renal glucose reabsorption during genetic and pharmacological SGLT2 inhibition in euglycemia. Am J Physiol Renal Physiol 306, F188-F193.

100. Oelze M, Kroller-Schon S, Welschof P, et al. (2014) The sodium-glucose co-transporter 2 inhibitor empagliflozin improves diabetes-induced vascular dysfunction in the streptozotocin diabetes rat model by interfering with oxidative stress and glucotoxicity. PLOS ONE 9, e112394.

101. Han Y, Cho YE, Ayon R, et al. (2015) SGLT inhibitors attenuate NO-dependent vascular relaxation in the pulmonary artery but not in the coronary artery. Am J Physiol Lung Cell Mol Physiol 309, L1027-L1036.

102. Wenzel P, Oelze M, Coldewey M, et al. (2007) Heme oxygenase-1: a novel key player in the development of tolerance in response to organic nitrates. Arterioscler Thromb Vasc Biol 27, 1729-1735.

103. Schuhmacher S, Oelze M, Bollmann F, et al. (2011) Vascular dysfunction in experimental diabetes is improved by pentaerithrityl tetranitrate but not isosorbide-5-mononitrate therapy. Diabetes 60, 2608-2616.

104. Hambrecht R, Wolf A, Gielen S, et al. (2000) Effect of exercise on coronary endothelial function in patients with coronary artery disease. $N$ Engl J Med 342, 454-460.

105. Fuchsjager-Mayrl G, Pleiner J, Wiesinger GF, et al. (2002) Exercise training improves vascular endothelial function in patients with type 1 diabetes. Diabetes Care 25, 1795-1801.

106. Colberg SR, Sigal RJ, Fernhall B, et al. (2010) Exercise and type 2 diabetes: the American College of Sports Medicine and the American Diabetes Association: joint position statement executive summary. Diabetes Care 33, 2692-2696.

107. Boule NG, Haddad E, Kenny GP, et al. (2001) Effects of exercise on glycemic control and body mass in type 2 diabetes mellitus: a meta-analysis of controlled clinical trials. JAMA 286, 1218-1227.

108. Lee S, Park Y \& Zhang C (2011) Exercise training prevents coronary endothelial dysfunction in type 2 diabetic mice. $\mathrm{Am}$ J Biomed Sci 3, 241-252.

109. May JM \& Qu ZC (2011) Ascorbic acid prevents oxidant-induced increases in endothelial permeability. Biofactors 37, 46-50.

110. Ceriello A, Piconi L, Esposito K, et al. (2007) Telmisartan shows an equivalent effect of vitamin $\mathrm{C}$ in further improving endothelial dysfunction after glycemia normalization in type 1 diabetes. Diabetes Care 30, 1694-1698.

111. Hoffman RP, Dye AS \& Bauer JA (2012) Ascorbic acid blocks hyperglycemic impairment of endothelial function in adolescents with type 1 diabetes. Pediatr Diabetes 13, 607-610.

112. Mason SA, Della Gatta PA, Snow RJ, et al. (2016) Ascorbic acid supplementation improves skeletal muscle oxidative stress and insulin sensitivity in people with type 2 diabetes: findings of a randomized controlled study. Free Radic Biol Med 93, 227-238.

113. Wotherspoon F, Laight DW, Turner C, et al. (2008) The effect of oral folic acid upon plasma homocysteine, endothelial function and oxidative stress in patients with type 1 diabetes and microalbuminuria. Int J Clin Pract 62, 569-574.

114. Sudchada P, Saokaew S, Sridetch S, et al. (2012) Effect of folic acid supplementation on plasma total homocysteine levels and glycemic control in patients with type 2 diabetes: a 
systematic review and meta-analysis. Diabetes Res Clin Pract 98, 151-158.

115. Wiltshire EJ, Gent R, Hirte C, et al. (2002) Endothelial dysfunction relates to folate status in children and adolescents with type 1 diabetes. Diabetes 51, 2282-2286.

116. Schneider MP, Schneider A, Jumar A, et al. (2014) Effects of folic acid on renal endothelial function in patients with diabetic nephropathy: results from a randomized trial. Clin Sci (Lond) 127, 499-505.

117. Ebbing M, Bonaa KH, Nygard O, et al. (2009) Cancer incidence and mortality after treatment with folic acid and vitamin $\mathrm{B}_{12}$. JAMA 302, 2119-2126.

118. Yiu YF, Yiu KH, Siu CW, et al. (2013) Randomized controlled trial of vitamin D supplement on endothelial function in patients with type 2 diabetes. Atherosclerosis 227, 140-146.

119. Alyami A, Soares MJ, Sherriff JL, et al. (2014) Vitamin D \& endothelial function. Indian J Med Res 140, 483-490.

120. Riek AE, Oh J, Sprague JE, et al. (2012) Vitamin D suppression of endoplasmic reticulum stress promotes an antiatherogenic monocyte/macrophage phenotype in type 2 diabetic patients. J Biol Chem 287, 38482-38494.

121. Dhein S, Kabat A, Olbrich A, et al. (2003) Effect of chronic treatment with vitamin $\mathrm{E}$ on endothelial dysfunction in a type I in vivo diabetes mellitus model and in vitro. J Pharmacol Exp Ther 305, 114-122.

122. Skyrme-Jones RA, O'Brien RC, Berry KL, et al. (2000) Vitamin E supplementation improves endothelial function in type I diabetes mellitus: a randomized, placebo-controlled study. J Am Coll Cardiol 36, 94-102.

123. Economides PA, Khaodhiar L, Caselli A, et al. (2005) The effect of vitamin $\mathrm{E}$ on endothelial function of micro- and macrocirculation and left ventricular function in type 1 and type 2 diabetic patients. Diabetes 54, 204-211.

124. Habauzit V \& Morand C (2012) Evidence for a protective effect of polyphenols-containing foods on cardiovascular health: an update for clinicians. Ther Adv Chronic Dis 3, 87-106.

125. Hoffman RP (2014) Vascular endothelial dysfunction and nutritional compounds in early type 1 diabetes. Curr Diabetes Rev 10, 201-207.

126. Gorinstein S, Caspi A, Libman I, et al. (2006) Red grapefruit positively influences serum triglyceride level in patients suffering from coronary atherosclerosis: studies in vitro and in humans. J Agric Food Chem 54, 1887-1892.

127. Geleijnse JM, Launer LJ, Van der Kuip DA, et al. (2002) Inverse association of tea and flavonoid intakes with incident myocardial infarction: the Rotterdam Study. Am J Clin Nutr 75, 880-886.

128. Manach C, Williamson G, Morand C, et al. (2005) Bioavailability and bioefficacy of polyphenols in humans. I. Review of 97 bioavailability studies. Am J Clin Nutr 81, 230S-242S.

129. Kroon PA, Clifford MN, Crozier A, et al. (2004) How should we assess the effects of exposure to dietary polyphenols in vitro? Am J Clin Nutr 80, 15-21.

130. Mooradian AD \& Haas MJ (2011) Glucose-induced endoplasmic reticulum stress is independent of oxidative stress: a mechanistic explanation for the failure of antioxidant therapy in diabetes. Free Radic Biol Med 50, 1140-1143.

131. Alderton WK, Cooper CE \& Knowles RG (2001) Nitric oxide synthases: structure, function and inhibition. Biochem J 357, 593-615.

132. Mount PF, Kemp BE \& Power DA (2007) Regulation of endothelial and myocardial NO synthesis by multi-site eNOS phosphorylation. J Mol Cell Cardiol 42, 271-279.

133. Barbosa VA, Luciano TF, Marques SO, et al. (2013) Acute exercise induce endothelial nitric oxide synthase phosphorylation via Akt and AMP-activated protein kinase in aorta of rats: role of reactive oxygen species. Int I Cardiol 167, 2983-2988.

134. Muniyappa R, Montagnani M, Koh KK, et al. (2007) Cardiovascular actions of insulin. Endocr Rev 28, 463-491.

135. Federici M, Pandolfi A, De Filippis EA, et al. (2004) G972R IRS-1 variant impairs insulin regulation of endothelial nitric oxide synthase in cultured human endothelial cells. Circulation 109, 399-405.

136. Jiang ZY, Lin YW, Clemont A, et al. (1999) Characterization of selective resistance to insulin signaling in the vasculature of obese Zucker (fa/fa) rats. J Clin Invest 104, 447-457.

137. Asaba K, Tojo A, Onozato ML, et al. (2005) Effects of NADPH oxidase inhibitor in diabetic nephropathy. Kidney Int $\mathbf{6 7}$, 1890-1898.

138. Beckman JS \& Koppenol WH (1996) Nitric oxide, superoxide, and peroxynitrite: the good, the bad, and ugly. Am J Physiol 271, C1424-C1437.

139. Liu Z, Jiang C, Zhang J, et al. (2015) Resveratrol inhibits inflammation and ameliorates insulin resistant endothelial dysfunction via regulation of AMP-activated protein kinase and sirtuin 1 activities. $J$ Diabetes $\mathbf{8}, 324-335$.

140. Arrick DM, Sun H, Patel KP, et al. (2011) Chronic resveratrol treatment restores vascular responsiveness of cerebral arterioles in type 1 diabetic rats. Am J Physiol Heart Circ Physiol 301, H696-H703.

141. Machha A, Achike FI, Mustafa AM, et al. (2007) Quercetin, a flavonoid antioxidant, modulates endothelium-derived nitric oxide bioavailability in diabetic rat aortas. Nitric Oxide 16, 442-447.

142. Zhao LR, Du YJ, Chen L, et al. (2014) Quercetin protects against high glucose-induced damage in bone marrow-derived endothelial progenitor cells. Int J Mol Med 34, 1025-1031.

143. Li PG, Sun L, Han X, et al. (2012) Quercetin induces rapid eNOS phosphorylation and vasodilation by an Akt-independent and PKA-dependent mechanism. Pharmacology 89, 220-228.

144. Tian S, Tang J, Liu H, et al. (2012) Propyl gallate plays a nephroprotective role in early stage of diabetic nephropathy associated with suppression of glomerular endothelial cell proliferation and angiogenesis. Exp Diabetes Res 2012, 209567.

145. Tian S, Gan Y, Li J, et al. (2011) Imbalance of glomerular VEGF-NO axis in diabetic rats: prevention by chronic therapy with propyl gallate. J Nephrol 24, 499-506.

146. Roghani M, Vaez Mahdavi MR, Jalali-Nadoushan MR, et al. (2013) Chronic administration of daidzein, a soybean isoflavone, improves endothelial dysfunction and attenuates oxidative stress in streptozotocin-induced diabetic rats. Phytother Res 27, 112-117.

147. Yin Y, Qi F, Song Z, et al. (2014) Ferulic acid combined with astragaloside IV protects against vascular endothelial dysfunction in diabetic rats. Biosci Trends $\mathbf{8}, 217-226$.

148. Rizza S, Muniyappa R, Iantorno M, et al. (2011) Citrus polyphenol hesperidin stimulates production of nitric oxide in endothelial cells while improving endothelial function and reducing inflammatory markers in patients with metabolic syndrome. J Clin Endocrinol Metab 96, E782-E792.

149. Jang HJ, Ridgeway SD \& Kim JA (2013) Effects of the green tea polyphenol epigallocatechin-3-gallate on high-fat diet-induced insulin resistance and endothelial dysfunction. Am J Physiol Endocrinol Metab 305, E1444-E1451.

150. Zhang W, Li R, Li J, et al. (2013) Alpha-linolenic acid exerts an endothelial protective effect against high glucose injury via PI3K/Akt pathway. PLOS ONE 8, e68489.

151. Bhardwaj P, Khanna D \& Balakumar P (2014) Catechin averts experimental diabetes mellitus-induced vascular endothelial 
structural and functional abnormalities. Cardiovasc Toxicol 14, 41-51.

152. Tang WJ, Hu CP, Chen MF, et al. (2006) Epigallocatechin gallate preserves endothelial function by reducing the endogenous nitric oxide synthase inhibitor level. Can J Physiol Pharmacol 84, 163-171.

153. Li Volti G, Salomone S, Sorrenti V, et al. (2011) Effect of silibinin on endothelial dysfunction and ADMA levels in obese diabetic mice. Cardiovasc Diabetol 10, 62.

154. Zhang M, Wang CM, Li J, et al. (2013) Berberine protects against palmitate-induced endothelial dysfunction: involvements of upregulation of AMPK and eNOS and downregulation of NOX4. Mediators Inflamm 2013, 260464.

155. Wang Y, Huang Y, Lam KS, et al. (2009) Berberine prevents hyperglycemia-induced endothelial injury and enhances vasodilatation via adenosine monophosphate-activated protein kinase and endothelial nitric oxide synthase. Cardiovasc Res 82, 484-492.

156. Ferrara N (2001) Role of vascular endothelial growth factor in regulation of physiological angiogenesis. Am J Physiol Cell Physiol 280, C1358-C1366.

157. Wirostko B, Wong TY \& Simo R (2008) Vascular endothelial growth factor and diabetic complications. Prog Retin Eye Res 27, 608-621.

158. Simo R \& Hernandez C (2008) Intravitreous anti-VEGF for diabetic retinopathy: hopes and fears for a new therapeutic strategy. Diabetologia 51, 1574-1580.

159. Schrijvers BF, Flyvbjerg A \& De Vriese AS (2004) The role of vascular endothelial growth factor (VEGF) in renal pathophysiology. Kidney Int 65, 2003-2017.

160. Nakagawa T, Kosugi T, Haneda M, et al. (2009) Abnormal angiogenesis in diabetic nephropathy. Diabetes $\mathbf{5 8}$ 1471-1478.

161. Yoon YS, Uchida S, Masuo O, et al. (2005) Progressive attenuation of myocardial vascular endothelial growth factor expression is a seminal event in diabetic cardiomyopathy: restoration of microvascular homeostasis and recovery of cardiac function in diabetic cardiomyopathy after replenishment of local vascular endothelial growth factor. Circulation 111, 2073-2085.

162. Verheyen A, Peeraer E, Lambrechts D, et al. (2013) Therapeutic potential of VEGF and VEGF-derived peptide in peripheral neuropathies. Neuroscience 244, 77-89.

163. Verheul HM \& Pinedo HM (2007) Possible molecular mechanisms involved in the toxicity of angiogenesis inhibition. Nat Rev Cancer 7, 475-485.

164. Mrudula T, Suryanarayana P, Srinivas PN, et al. (2007) Effect of curcumin on hyperglycemia-induced vascular endothelial growth factor expression in streptozotocin-induced diabetic rat retina. Biochem Biophys Res Commun 361, 528-532.

165. Kowluru RA \& Kanwar M (2007) Effects of curcumin on retinal oxidative stress and inflammation in diabetes. Nutr Metab (Lond) $\mathbf{4}, 8$.

166. Sawatpanich T, Petpiboolthai H, Punyarachun B, et al. (2010) Effect of curcumin on vascular endothelial growth factor expression in diabetic mice kidney induced by streptozotocin. J Med Assoc Thai 93, Suppl. 2, S1-S8.

167. Shin JY, Sohn J \& Park KH (2013) Chlorogenic acid decreases retinal vascular hyperpermeability in diabetic rat model. J Korean Med Sci 28, 608-613.

168. Wang Y, Pampou S, Fujikawa K, et al. (2004) Opposing effect of angiopoietin-1 on VEGF-mediated disruption of endothelial cell-cell interactions requires activation of PKC beta. J Cell Physiol 198, 53-61.

169. Premanand C, Rema M, Sameer MZ, et al. (2006) Effect of curcumin on proliferation of human retinal endothelial cells under in vitro conditions. Invest Ophthalmol Vis Sci $\mathbf{4 7}$, 2179-2184.

170. Chen J, Dai M \& Wang Y (2014) Paeonol inhibits proliferation of vascular smooth muscle cells stimulated by high glucose via Ras-Raf-ERK1/2 signaling pathway in coculture model. Evid Based Complement Alternat Med 2014, 484269.

171. Gao R, Zhu BH, Tang SB, et al. (2008) Scutellarein inhibits hypoxia- and moderately-high glucose-induced proliferation and VEGF expression in human retinal endothelial cells. Acta Pharmacol Sin 29, 707-712.

172. Tian C, Zhang R, Ye X, et al. (2013) Resveratrol ameliorates high-glucose-induced hyperpermeability mediated by caveolae via VEGF/KDR pathway. Genes Nutr $\mathbf{8}$, 231-239.

173. Artwohl M, Muth K, Kosulin K, et al. (2007) R-(+)-alphalipoic acid inhibits endothelial cell apoptosis and proliferation: involvement of Akt and retinoblastoma protein/E2F-1. Am J Physiol Endocrinol Metab 293, E681-E689.

174. Simons M (2005) Angiogenesis, arteriogenesis, and diabetes: paradigm reassessed? J Am Coll Cardiol 46, 835-837.

175. Lerman OZ, Galiano RD, Armour M, et al. (2003) Cellular dysfunction in the diabetic fibroblast: impairment in migration, vascular endothelial growth factor production, and response to hypoxia. Am J Pathol 162, 303-312.

176. Naruse K, Rask-Madsen C, Takahara N, et al. (2006) Activation of vascular protein kinase C-beta inhibits Akt-dependent endothelial nitric oxide synthase function in obesity-associated insulin resistance. Diabetes 55, 691-698.

177. Park CW, Kim HW, Lim JH, et al. (2009) Vascular endothelial growth factor inhibition by dRK6 causes endothelial apoptosis, fibrosis, and inflammation in the heart via the Akt/eNOS axis in $\mathrm{db} / \mathrm{db}$ mice. Diabetes $\mathbf{5 8}$, 2666-2676.

178. Nakamura N, Naruse K, Kobayashi Y, et al. (2011) High glucose impairs the proliferation and increases the apoptosis of endothelial progenitor cells by suppression of Akt. J Diabetes Investig 2, 262-270

179. Tufro A \& Veron D (2012) VEGF and podocytes in diabetic nephropathy. Semin Nephrol 32, 385-393.

180. Yang Z, Mo X, Gong Q, et al. (2008) Critical effect of VEGF in the process of endothelial cell apoptosis induced by high glucose. Apoptosis 13, 1331-1343.

181. Yang KS, Lim JH, Kim TW, et al. (2014) Vascular endothelial growth factor-receptor 1 inhibition aggravates diabetic nephropathy through eNOS signaling pathway in $\mathrm{db} /$ db mice. PLOS ONE 9, e94540.

182. Nakagawa T, Sato W, Kosugi T, et al. (2013) Uncoupling of VEGF with endothelial $\mathrm{NO}$ as a potential mechanism for abnormal angiogenesis in the diabetic nephropathy. J Diabetes Res 2013, 184539.

183. Benyair R, Ron E \& Lederkremer GZ (2011) Protein quality control, retention, and degradation at the endoplasmic reticulum. Int Rev Cell Mol Biol 292, 197-280.

184. Luo D, He Y, Zhang H, et al. (2008) AIP1 is critical in transducing IRE1-mediated endoplasmic reticulum stress response. J Biol Chem 283, 11905-11912.

185. Gharavi NM, Gargalovic PS, Chang I, et al. (2007) High-density lipoprotein modulates oxidized phospholipid signaling in human endothelial cells from proinflammatory to anti-inflammatory. Arterioscler Thromb Vasc Biol 27, 1346-1353.

186. Friedlander R, Jarosch E, Urban J, et al. (2000) A regulatory link between ER-associated protein degradation and the unfolded-protein response. Nat Cell Biol 2, 379-384. 
187. Parmar VM \& Schroder M (2012) Sensing endoplasmic reticulum stress. Adv Exp Med Biol 738, 153-168.

188. Yoneda T, Imaizumi K, Oono K, et al. (2001) Activation of caspase-12, an endoplastic reticulum (ER) resident caspase, through tumor necrosis factor receptor-associated factor 2-dependent mechanism in response to the ER stress. $\mathrm{J}$ Biol Chem 276, 13935-13940.

189. Xu C, Bailly-Maitre B \& Reed JC (2005) Endoplasmic reticulum stress: cell life and death decisions. J Clin Invest 115, 2656-2664.

190. McCullough KD, Martindale JL, Klotz LO, et al. (2001) Gadd153 sensitizes cells to endoplasmic reticulum stress by down-regulating $\mathrm{Bcl} 2$ and perturbing the cellular redox state. Mol Cell Biol 21, 1249-1259.

191. Chen Y, Wang JJ, Li J, et al. (2012) Activating transcription factor 4 mediates hyperglycaemia-induced endothelial inflammation and retinal vascular leakage through activation of STAT3 in a mouse model of type 1 diabetes. Diabetologia 55, 2533-2545.

192. Tsiotra PC \& Tsigos C (2006) Stress, the endoplasmic reticulum, and insulin resistance. Ann NY Acad Sci 1083, 63-76.

193. Zhang X, Fu Y, Xu X, et al. (2014) PERK pathway are involved in NO-induced apoptosis in endothelial cells cocultured with RPE under high glucose conditions. Nitric Oxide 40, 10-16.

194. Kaufman RJ (2002) Orchestrating the unfolded protein response in health and disease. J Clin Invest 110, 1389-1398.

195. Li J, Wang JJ, Yu Q, et al. (2009) Endoplasmic reticulum stress is implicated in retinal inflammation and diabetic retinopathy. FEBS Lett 583, 1521-1527.

196. Salminen A, Kauppinen A, Hyttinen JM, et al. (2010) Endoplasmic reticulum stress in age-related macular degeneration: trigger for neovascularization. Mol Med 16, 535-542.

197. Wang S, Park JK \& Duh EJ (2012) Novel targets against retinal angiogenesis in diabetic retinopathy. Curr Diab Rep 12, 355-363.

198. Sheikh-Ali M, Sultan S, Alamir AR, et al. (2010) Effects of antioxidants on glucose-induced oxidative stress and endoplasmic reticulum stress in endothelial cells. Diabetes Res Clin Pract 87, 161-166.

199. Song J, Li J, Hou F, et al. (2015) Mangiferin inhibits endoplasmic reticulum stress-associated thioredoxin-interacting protein/ NLRP3 inflammasome activation with regulation of AMPK in endothelial cells. Metabolism 64, 428-437.

200. Guo H, Callaway JB \& Ting JP (2015) Inflammasomes: mechanism of action, role in disease, and therapeutics. Nat Med 21, 677-687.

201. Takeuchi O \& Akira S (2010) Pattern recognition receptors and inflammation. Cell 140, 805-820.

202. Mohamed IN, Hafez SS, Fairaq A, et al. (2014) Thioredoxininteracting protein is required for endothelial NLRP3 inflammasome activation and cell death in a rat model of high-fat diet. Diabetologia 57, 413-423.

203. Wu J, Xu X, Li Y, et al. (2014) Quercetin, luteolin and epigallocatechin gallate alleviate TXNIP and NLRP3-mediated inflammation and apoptosis with regulation of AMPK in endothelial cells. Eur $J$ Pharmacol $\mathbf{7 4 5}$, 59-68.

204. Li Y, Yang J, Chen MH, et al. (2015) Ilexgenin A inhibits endoplasmic reticulum stress and ameliorates endothelial dysfunction via suppression of TXNIP/NLRP3 inflammasome activation in an AMPK dependent manner. Pharmacol Res 99, 101-115.

205. Zhao Y, Li Q, Zhao W, et al. (2015) Astragaloside IV and cycloastragenol are equally effective in inhibition of endoplasmic reticulum stress-associated TXNIP/NLRP3 inflammasome activation in the endothelium. J Ethnopharmacol 169, 210-218.

206. Natsume Y, Ito S, Satsu H, et al. (2009) Protective effect of quercetin on ER stress caused by calcium dynamics dysregulation in intestinal epithelial cells. Toxicology 258, 164-175.

207. Reiling JH, Clish CB, Carette JE, et al. (2011) A haploid genetic screen identifies the major facilitator domain containing 2A (MFSD2A) transporter as a key mediator in the response to tunicamycin. Proc Natl Acad Sci U S A 108, 11756-11765.

208. Szegezdi E, Logue SE, Gorman AM, et al. (2006) Mediators of endoplasmic reticulum stress-induced apoptosis. EMBO Rep 7, 880-885.

209. Suganya N, Bhakkiyalakshmi E, Suriyanarayanan S, et al. (2014) Quercetin ameliorates tunicamycin-induced endoplasmic reticulum stress in endothelial cells. Cell Prolif 47, 231-240.

210. Cuzzocrea S (2005) Shock, inflammation and PARP. Pharmacol Res 52, 72-82.

211. Buluc M \& Demirel-Yilmaz E (2006) Resveratrol decreases calcium sensitivity of vascular smooth muscle and enhances cytosolic calcium increase in endothelium. Vascul Pharmacol 44, 231-237.

212. Li C, Wang L, Huang K, et al. (2012) Endoplasmic reticulum stress in retinal vascular degeneration: protective role of resveratrol. Invest Ophthalmol Vis Sci 53, 3241-3249.

213. Du XL, Edelstein D, Rossetti L, et al. (2000) Hyperglycemiainduced mitochondrial superoxide overproduction activates the hexosamine pathway and induces plasminogen activator inhibitor-1 expression by increasing Sp1 glycosylation. Proc Natl Acad Sci U S A 97, 12222-12226.

214. Durier S, Fassot C, Laurent S, et al. (2003) Physiological genomics of human arteries: quantitative relationship between gene expression and arterial stiffness. Circulation 108, 1845-1851.

215. Gao L \& Mann GE (2009) Vascular NAD(P)H oxidase activation in diabetes: a double-edged sword in redox signalling. Cardiovasc Res 82, 9-20.

216. Amiri F, Virdis A, Neves MF, et al. (2004) Endotheliumrestricted overexpression of human endothelin-1 causes vascular remodeling and endothelial dysfunction. Circulation 110, 2233-2240.

217. Rahman A \& Fazal F (2011) Blocking NF-kappaB: an inflammatory issue. Proc Am Thorac Soc 8, 497-503.

218. Viatour P, Merville MP, Bours V, et al. (2005) Phosphorylation of NF-kappaB and IkappaB proteins: implications in cancer and inflammation. Trends Biochem Sci 30, 43-52.

219. Xiao L, Liu $\mathrm{Y}$ \& Wang N (2014) New paradigms in inflammatory signaling in vascular endothelial cells. $A m \mathrm{~J}$ Physiol Heart Circ Physiol 306, H317-H325.

220. Takaishi H, Taniguchi T, Takahashi A, et al. (2003) High glucose accelerates MCP-1 production via p38 MAPK in vascular endothelial cells. Biochem Biophys Res Commun 305, 122-128.

221. Natali A, Toschi E, Baldeweg S, et al. (2006) Clustering of insulin resistance with vascular dysfunction and low-grade inflammation in type 2 diabetes. Diabetes $\mathbf{5 5}$, $1133-1140$

222. Zhang H, Dellsperger KC \& Zhang C (2012) The link between metabolic abnormalities and endothelial dysfunction in type 2 diabetes: an update. Basic Res Cardiol 107, 237.

223. Csiszar A, Smith K, Labinskyy N, et al. (2006) Resveratrol attenuates TNF-alpha-induced activation of coronary arterial 
endothelial cells: role of NF-kappaB inhibition. Am J Physiol Heart Circ Physiol 291, H1694-H1699.

224. Dayoub O, Andriantsitohaina R \& Clere N (2013) Pleiotropic beneficial effects of epigallocatechin gallate, quercetin and delphinidin on cardiovascular diseases associated with endothelial dysfunction. Cardiovasc Hematol Agents Med Chem 11, 249-264.

225. Wongeakin N, Bhattarakosol P \& Patumraj S (2014) Molecular mechanisms of curcumin on diabetes-induced endothelial dysfunctions: Txnip, ICAM-1, and NOX2 expressions. Biomed Res Int 2014, 161346.

226. Gupta SK, Kumar B, Nag TC, et al. (2011) Curcumin prevents experimental diabetic retinopathy in rats through its hypoglycemic, antioxidant, and anti-inflammatory mechanisms. J Ocul Pharmacol Ther 27, 123-130.

227. Rungseesantivanon S, Thenchaisri N, Ruangvejvorachai $P$, et al. (2010) Curcumin supplementation could improve diabetes-induced endothelial dysfunction associated with decreased vascular superoxide production and PKC inhibition. BMC Complement Altern Med 10, 57.

228. Mahmoud MF, Hassan NA, El Bassossy HM, et al. (2013) Quercetin protects against diabetes-induced exaggerated vasoconstriction in rats: effect on low grade inflammation. PLOS ONE 8, e63784.

229. Yamagata K, Miyashita A, Matsufuji H, et al. (2010) Dietary flavonoid apigenin inhibits high glucose and tumor necrosis factor alpha-induced adhesion molecule expression in human endothelial cells. J Nutr Biochem 21, $116-124$.

230. Tuttle KR \& Anderson PW (2003) A novel potential therapy for diabetic nephropathy and vascular complications: protein kinase $\mathrm{C}$ beta inhibition. Am J Kidney Dis $\mathbf{4 2}$, 456-465.

231. Yang J, Han Y, Chen C, et al. (2013) EGCG attenuates high glucose-induced endothelial cell inflammation by suppression of PKC and NF-kappaB signaling in human umbilical vein endothelial cells. Life Sci $\mathbf{9 2}$, 589-597.

232. Kim SW, Kim CE \& Kim MH (2011) Flavonoids inhibit high glucose-induced up-regulation of ICAM-1 via the p38 MAPK pathway in human vein endothelial cells. Biochem Biophys Res Commun 415, 602-607.

233. Gao Y, Zhang J, Li G, et al. (2015) Protection of vascular endothelial cells from high glucose-induced cytotoxicity by emodin. Biochem Pharmacol 94, 39-45.

234. Jayakumar T, Chang CC, Lin SL, et al. (2014) Brazilin ameliorates high glucose-induced vascular inflammation via inhibiting ROS and CAMs production in human umbilical vein endothelial cells. Biomed Res Int 2014, 403703.

235. Lee W, Ku SK, Lee D, et al. (2014) Emodin-6-O-beta-D glucoside inhibits high-glucose-induced vascular inflammation. Inflammation 37, 306-313.

236. Xiong Y, Wang GF, Zhang JY, et al. (2010) [Naringin inhibits monocyte adhesion to high glucose-induced human umbilical vein endothelial cells]. Nan Fang Yi Ke Da Xue Xue Bao 30, 321-325.

237. Kwak S, Ku SK \& Bae JS (2014) Fisetin inhibits high-glucoseinduced vascular inflammation in vitro and in vivo. Inflamm Res $\mathbf{6 3}, 779-787$.

238. Ku SK, Kwak S \& Bae JS (2014) Orientin inhibits high glucose-induced vascular inflammation in vitro and in vivo. Inflammation 37, 2164-2173.

239. Ku SK \& Bae JS (2015) Baicalin, baicalein and wogonin inhibits high glucose-induced vascular inflammation in vitro and in vivo. BMB Rep 48, 519-524.
240. Zheng X, Zhu S, Chang S, et al. (2013) Protective effects of chronic resveratrol treatment on vascular inflammatory injury in steptozotocin-induced type 2 diabetic rats: role of NF-kappa B signaling. Eur J Pharmacol $\mathbf{7 2 0}$, 147-157.

241. Babu PV, Si H, Fu Z, et al. (2012) Genistein prevents hyperglycemia-induced monocyte adhesion to human aortic endothelial cells through preservation of the cAMP signaling pathway and ameliorates vascular inflammation in obese diabetic mice. J Nutr 142, 724-730.

242. Margina D, Gradinaru D, Manda G, et al. (2013) Membranar effects exerted in vitro by polyphenols - quercetin, epigallocatechin gallate and curcumin - on HUVEC and Jurkat cells, relevant for diabetes mellitus. Food Chem Toxicol 61, 86-93.

243. Cho HY, Reddy SP \& Kleeberger SR (2006) Nrf2 defends the lung from oxidative stress. Antioxid Redox Signal 8, 76-87.

244. Zhang DD (2006) Mechanistic studies of the Nrf2-Keap1 signaling pathway. Drug Metab Rev 38, 769-789.

245. Chen XL, Varner SE, Rao AS, et al. (2003) Laminar flow induction of antioxidant response element-mediated genes in endothelial cells. A novel anti-inflammatory mechanism. $J$ Biol Chem 278, 703-711.

246. Afonyushkin T, Oskolkova OV, Philippova M, et al. (2010) Oxidized phospholipids regulate expression of ATF4 and VEGF in endothelial cells via NRF2-dependent mechanism: novel point of convergence between electrophilic and unfolded protein stress pathways. Arterioscler Thromb Vasc Biol 30, 1007-1013.

247. Luo Z, Aslam S, Welch WJ, et al. (2015) Activation of nuclear factor erythroid 2-related factor 2 coordinates dimethylarginine dimethylaminohydrolase/PPAR-gamma/endothelial nitric oxide synthase pathways that enhance nitric oxide generation in human glomerular endothelial cells. Hypertension 65, 896-902.

248. Zhong Q, Mishra M \& Kowluru RA (2013) Transcription factor Nrf2-mediated antioxidant defense system in the development of diabetic retinopathy. Invest Ophthalmol Vis Sci 54, 3941-3948.

249. Ungvari Z, Bailey-Downs L, Gautam T, et al. (2011) Adaptive induction of NF-E2-related factor-2-driven antioxidant genes in endothelial cells in response to hyperglycemia. Am J Physiol Heart Circ Physiol 300, H1133-H1140.

250. Suh JH, Shenvi SV, Dixon BM, et al. (2004) Decline in transcriptional activity of $\mathrm{Nrf} 2$ causes age-related loss of glutathione synthesis, which is reversible with lipoic acid. Proc Natl Acad Sci U S A 101, 3381-3386.

251. Jiang T, Huang Z, Lin Y, et al. (2010) The protective role of Nrf2 in streptozotocin-induced diabetic nephropathy. Diabetes 59, 850-860.

252. Okouchi M, Okayama N, Alexander JS, et al. (2006) NRF2dependent glutamate-L-cysteine ligase catalytic subunit expression mediates insulin protection against hyperglycemia- induced brain endothelial cell apoptosis. Curr Neurovasc Res 3, 249-261.

253. Yoh K, Hirayama A, Ishizaki K, et al. (2008) Hyperglycemia induces oxidative and nitrosative stress and increases renal functional impairment in Nrf2-deficient mice. Genes Cells $\mathbf{1 3}$, $1159-1170$

254. Ungvari Z, Bagi Z, Feher A, et al. (2010) Resveratrol confers endothelial protection via activation of the antioxidant transcription factor Nrf2. Am J Physiol Heart Circ Physiol 299, H18-H24.

255. Velmurugan GV, Sundaresan NR, Gupta MP, et al. (2013) Defective Nrf2-dependent redox signalling contributes to 
microvascular dysfunction in type 2 diabetes. Cardiovasc Res 100, 143-150.

256. Lee SE, Yang $\mathrm{H}$, Son $\mathrm{GW}$, et al. (2015) Eriodictyol protects endothelial cells against oxidative stress-induced cell death through modulating ERK/Nrf2/ARE-dependent heme oxygenase-1 expression. Int J Mol Sci 16, 14526-14539.

257. Ganesh Yerra V, Negi G, Sharma SS, et al. (2013) Potential therapeutic effects of the simultaneous targeting of the Nrf2 and NF-kappaB pathways in diabetic neuropathy. Redox Biol 1, 394-397.

258. Xue M, Qian Q, Adaikalakoteswari A, et al. (2008) Activation of NF-E2-related factor-2 reverses biochemical dysfunction of endothelial cells induced by hyperglycemia linked to vascular disease. Diabetes 57, 2809-2817.
259. Negi G, Kumar A \& Sharma SS (2011) Nrf2 and NF-kappaB modulation by sulforaphane counteracts multiple manifestations of diabetic neuropathy in rats and high glucoseinduced changes. Curr Neurovasc Res 8, 294-304.

260. Kant V, Gopal A, Kumar D, et al. (2015) Curcumin-induced angiogenesis hastens wound healing in diabetic rats. J Surg Res 193, 978-988.

261. Babu PV, Si H \& Liu D (2012) Epigallocatechin gallate reduces vascular inflammation in $\mathrm{db} / \mathrm{db}$ mice possibly through an NF-kappaB-mediated mechanism. Mol Nutr Food Res 56, 1424-1432.

262. Wen D, Huang X, Zhang M, et al. (2013) Resveratrol attenuates diabetic nephropathy via modulating angiogenesis. PLOS ONE 8, e82336. 